\title{
We're Number 1: \\ Price Wars for Market Share Leadership
}

\author{
Luís Cabral \\ New York University and CEPR
}

January 2014

\begin{abstract}
I examine the dynamics of oligopolies when firms derive subjective value from being the market leader. In equilibrium, prices alternate in tandem between high levels and occasional price wars, which take place when market shares are similar and market leadership is at stake. The stationary distribution of market shares is typically multimodal, that is, much of the time there is a stable market leader. Even though shareholders do not value market leadership per se, a corporate culture that values market leadership may increase shareholder value. From a competition policy point of view, the paper implies that price regime change dynamics and parallel pricing are consistent with competitive behavior — in fact, hyper-competitive behavior.
\end{abstract}

Keywords: dynamic oligopoly, price wars, market shares, ordinal rankings, behavioral IO

JEL Classification: L13, L21

Paganelli-Bull Professor of Economics and International Business, Stern School of Business, New York University; IME and PSPS Research Fellow, IESE; and Research Fellow, CEPR (London); luis.cabral@nyu.edu. I am grateful to Glenn Ellison, Michael Katz, Dmitri Kuksov, Francisco Ruiz-Aliseda, Paulo Somaini, Brian $\mathrm{Wu}$, and participants at various seminars and conferences for helpful comments. The usual disclaimer applies. 


\section{Introduction}

In many industries, the prevailing managerial attitude places a disproportionate weight on being \#1 - the market share leader. For example, in May 2012 Airbus "accused Boeing of trying to start a price war after the U.S. company pledged to work aggressively to regain a $50 \%$ share of the market." A February 2011 headline announced that "IBM reclaims server market share revenue crown in Q4," adding that "IBM and HP will continue to duke it out." According to CNN, "GM held onto its No. 1 rank by cutting prices on cars to the point where they were unprofitable." And during a 2007 interview with a group of bloggers, SAP CEO Henning Kagermann stated, "We are not arrogant, we are the market leader." 1

In this paper, I examine the implications of ordinal comparisons, in particular the \#1 bias, for market competition. Specifically, I examine the behavior of managers who receive an extra utility kick from being market share leaders. ${ }^{2}$ (I do not develop a theory to explain why managers derive utility from being market leaders, though I discuss some rational and behavioral reasons for this pattern.)

I develop a model with two sellers and multiple buyers, all of whom live forever. Buyers reassess their choice of seller at random points in time. Buyers have preference for sellers and for money. Sellers have a preference for money and for being \#1. I show that a simple model as this leads to a rich theory of price wars and the evolution of market shares. I also show that a corporate culture that emphasizes the importance of market leadership may increase shareholder value even if shareholders do not care about market leadership (or market shares) per se.

Specifically, I show that a firm's utility from begin market leader implies a price drop when market shares are close to $50 \%$, and thus a lot is at stake. Moreover, I provide conditions such that, fearful of entering into a price war, competition is softened at states close to the price war region - so much so that shareholder value increases with respect to the no \#1 effects regime. The softening of price competition also implies that the stationary distribution of market shares is bimodal, that is, most of the time one firm is larger than the other one - and occasionally price wars for market share take place.

My analysis has important implications for competition policy. The economics literature typically identifies price war dynamics with collusive equilibria (that is, prices alternating between collusive and competitive levels). In my model, there is no explicit or tacit collusive agreement between firms; prices alternate between competitive and "hyper-competitive" levels (that is, \#1 effects lead to lower prices than under "normal" competitive conditions). The economics literature also tends to identify parallel pricing with tacit collusion. My model too produces correlated price changes (in the limit, perfectly correlated price changes) even though there is no collusion or communication between firms: each firm's price is a function of market shares, and movements in market shares induce simultaneous moves in prices - even though there is no collusion.

My paper also has implications for an central question in industrial organization and strategy: the persistence of differences across firms. Typically these are explained by primi-

1. Ferrier and Smith (1999) quote a series of Wall Street Journal headlines (though no formal cites are supplied), including "Alex Trotman's goal: To make Ford No. 1 in world auto sales;" "Kellogg's cutting prices ... to check loss of market share;" and "Amoco scrambles to remain king of the polyester hill."

2. In Section 4, I also examine the behavior of managers who sell to consumers who get an extra utility kick from buying from a market share leader. 
tive differences across firms (e.g., unique resources); endogenous difference dues to increasing returns (e.g., learning curves or network effects); or stickiness in market shares (e.g., switching costs). My model features none of the above and still induces a stationary distribution of market shares that can be bi-modal. In other words, for a "long" period of time, there is a large firm and a small firm; and the only barrier to mobility that stops the small firm from becoming large is the price war it must go through in order to increase market share.

- Related literature and contribution. The paper makes several contributions to the industrial organization and strategy literatures. First, it studies the implications of a fairly pervasive phenomenon, namely firms' desire to be market share leaders. Baumol (1962) and others have developed models where firms follow objectives other than profit maximization. However, to the best of my knowledge this is the first paper in the industrial organization literature explicitly to consider pricing dynamics when \#1 effects are in place.

Second, I develop a realistic theory of price wars. For all of the richness of industrial organization theory, the core theory of price wars is still connected almost exclusively to collusion models. In Green and Porter (1982), price wars result from the breakdown of collusive equilibria during periods of (unobservable) low demand. Rotemberg and Saloner (1985) suggest that price wars correspond to firms refraining from collusion during periods of observable high demand. By contrast, I assume that firms do not collude (they play Markov strategies). Instead of a repeated game, I assume firms play a dynamic game where the state is defined by each firm's market share. In this context, price wars emerge in states where a firms' value function is particularly steep, that is, during periods when a firm's gain from increasing market share is particularly high. In this sense, the pricing equilibrium in my model bears some resemblance to models with learning or network effects (Cabral and Riordan, 1994; Besanko, Doraszelski, Kryukov and Satterthwaite, 2010; Cabral, 2011). However, the dynamics in these papers are driven by increasing returns, whereas I consider a setting with constant returns to scale.

Third, I provide an instance where corporate culture has a clear influence on the way firms compete. Specifically, I provide conditions such that a deviation from profit maximization may in effect lead to higher firm value. Vickers (1985), Fershtman and Judd (1987) and Sklivas (1987) have shown that profit seeking shareholders may have an interest in delegating decisions to managers based on incentive mechanisms that differ from profit maximization. ${ }^{3}$ Specifically, if the firms' decision variables are strategic complements (as is the case in my model) then equilibrium delegation contracts ask managers to pay less importance to profits than shareholders would: such contracts "soften" price competition and lead to overall higher profits than in the "normal" price competition game. My approach is very different, and so are the results, essentially because my approach is dynamic, whereas Vickers' (1985), Fershtman and Judd's (1987) and Sklivas' (1987) is static. Specifically, \#1 effects ask firms to place more weight on market shares than shareholders would. This makes firms more, not less, aggressive. From a static point of view, this effect is bad news

3. The idea goes back to (at least) Shelling's (1960) observation that

The use of thugs or sadists for the collection of extortion or the guarding of prisoners, or the conspicuous delegation of authority to a military commander of known motivation, exemplifies a common means of making credible a response pattern that the original source of decision might have been thought to shrink from or to find profitless, once the threat had failed. 
for shareholders, for excessively aggressive pricing means lower equilibrium profits. However, the price wars that follow from \#1 effects are rare; and the negative effect of overly aggressive pricing is more than compensated by the deterrence effect that the threat of a price war has when firms are in an asymmetric state. In this sense, my results relate to the so-called topsy-turvy principle in collusion through repeated interaction (Shapiro, 1989): the greater the credible punishment that firms can find, the greater the equilibrium profit they can sustain under collusion.

My paper is also related to three other strands of the economics literature. First, the literature on dynamic oligopoly competition. In this context, continuation value functions are typically increasing in current market shares and there is a trade off between current profit and future market share (sometimes referred to as market share "harvesting" and market share "investing"). Examples of this pattern include switching costs (Klemperer, 1987), learning curves (Cabral and Riordan, 1994), and network effects (Cabral, 2011). \#1 effects provide an additional reason why firms care about market shares. One important difference of my approach is that a firm's value function may not be monotonic with respect to market shares: even though each period's payoff is increasing in market shares, a small firm's prospect of entering into a price war with a large firm may imply that its continuation value be decreasing in market share.

Second, the paper relates to the literatures on tournaments and races. Beginning with Lazear and Rosen (1981), nearly all of the economics applications of tournaments have been limited to issues of personnel economics. By contrast, I consider the case when market competition is a sort of tournament where ordinal relative positioning matters (in addition to profits). The racing literature derives patterns of firm effort as a function of relative positioning. For example, differently from my model, Hörner (2004) shows that it is generally not true that competition is fiercest when firms are closest.

Finally, my work also relates to the recent literature on behavior industrial organization. Most of this literature deals with cases when consumer behavior departs from full information and full rationality (see Ellison, 2005, for a survey). Some papers deal with the case when competing firms behave behaviorally. For example, Al-Najjar, Baliga and Besanko (2008) consider the case when firms cannot distinguish between different types of cost (fixed, sunk, variable), which leads to distorted pricing decisions. Armstrong and Huck( 2010) survey a few additional papers where managers have non-standard preferences (e.g., they care for relative performance). To the best of my knowledge, my work is the first attempt at studying the effects of a market leadership bias.

- Roadmap. The rest of the paper is structured as follows. In Section 2 I present the basic model. Section 4 discusses robustness analysis and extensions. Section 5 concludes the paper.

\section{Model}

Consider a duopoly with two firms, $a$ and $b$. I will use $i$ and $j$ to designate a firm generically, that is, $i, j=a, b$. Time is discrete and runs indefinitely: $t=1,2, \ldots$ The total number of consumers is given by $\eta$.

The model dynamics are given by the assumption that agents make "durable" decisions infrequently. Specifically, at random moments in time a consumer is called to re-assess 
its decision regarding the firm it buys from. One way to think about this is that each consumer's switching cost follows a stochastic process, alternating between the values of infinity (inactive consumer) to zero (active consumer). Alternatively, I may assume that consumers leave the market (death) and are replaced by new consumers in equal number (birth). ${ }^{4}$

The timing of this process is described in Figure 1. Each period starts with each firm having a certain number of consumers, $i$ and $j$, attached to it (where $i+j=\eta$ ). Firms set prices $p(i)$ and $p(j)$. I constrain prices to be a function of the state $(i, j)$, that is, I restrict firms to play Markov strategies. Since the total number of consumers is constant, the state space is one-dimensional and can be summarized by $i$.

After firms set prices, Nature chooses a particular agent, whom I will call the "active" agent. Each agent becomes active with equal probability. Then Nature generates the active agent's preferences: values $\zeta_{a}$ and $\zeta_{b}$, corresponding to consumer specific preference for each firm's product. I assume these values are i.i.d., drawn from a cdf $\Omega(\zeta)$ and that $\xi \equiv \zeta_{a}-\zeta_{b}$ is distributed according to cdf $\Phi(\cdot){ }^{5}$ The active consumer then chooses one of the firms and period payoffs from sales are paid: the sale price to the firm that makes a sale and utility minus price to the consumer who makes a purchase.

In addition to sales revenues, I assume that firm $i$ receives an extra benefit $\theta$ if it is the market leader, that is, if $i>j$. In order to preserve model symmetry, I also assume that, if $i<j$, then firm $i$ receives an extra negative benefit $\theta$; and that if $i=j$ then both firms receive zero extra benefit. This assumption guarantees that, regardless of the state, the firms' joint payoff from market leadership is zero. Market leadership payoff may be summarized by $\theta \Delta(i)$, where $\Delta(i)$ is an indicator variable defined as follows:

$$
\Delta(i) \equiv \operatorname{sgn}(i-j)=\left\{\begin{aligned}
+1 & \text { if } i>j \\
0 & \text { if } i=j \\
-1 & \text { if } i<j
\end{aligned}\right.
$$

where $j=\eta-i$. Recall that this term does not correspond to "real" value, rather it is simply value perceived by firm $i$ 's managers. ${ }^{6}$

There are two sources of randomness in the model. One is that each period one consumer is selected by Nature to be an active consumer. Second, Nature generates utility shocks for the active agent such that the difference $\xi_{i} \equiv \zeta_{i}-\zeta_{j}$ is distributed according to cdf $\Phi(\xi)$. Many of the results below require relatively mild assumptions regarding $\Phi$ :

Assumption 1. (i) $\Phi(\xi)$ is continuously differentiable; (ii) $\phi(\xi)=\phi(-\xi)$; (iii) $\phi(\xi)>0, \forall \xi$; (iv) $\Phi(\xi) / \phi(\xi)$ is strictly increasing.

4. Similarly to Cabral (2011), the assumption of discrete time with exactly one consumer being "active" in each period may be interpreted as the reduced form of a continuous time model where each consumer becomes "active" with a constant hazard rate $\nu$. The relevant discount factor is then computed as $\delta \equiv \eta \nu /(r+\eta \nu)$, where $r$ is the continuous time interest rate.

5. Under the model interpretation that consumers are born and die, the i.i.d. assumption seems reasonable. Under the active/inactive consumer assumption, this assumption has the unreasonable implication that the preferences of an active consumer are independent of its previous preferences. In this sense, my model may be seen as an approximation or as assuming that consumers and firms do not take this time correlation into account when computing value functions.

6. In Section 4, I consider the possibility that consumers derive utility from purchasing from a market share leader, that is, consumers derive utility $\lambda \Delta(i)$ in addition to the $\zeta_{i}-p(i)$ term considered above. 
Figure 1

Timing

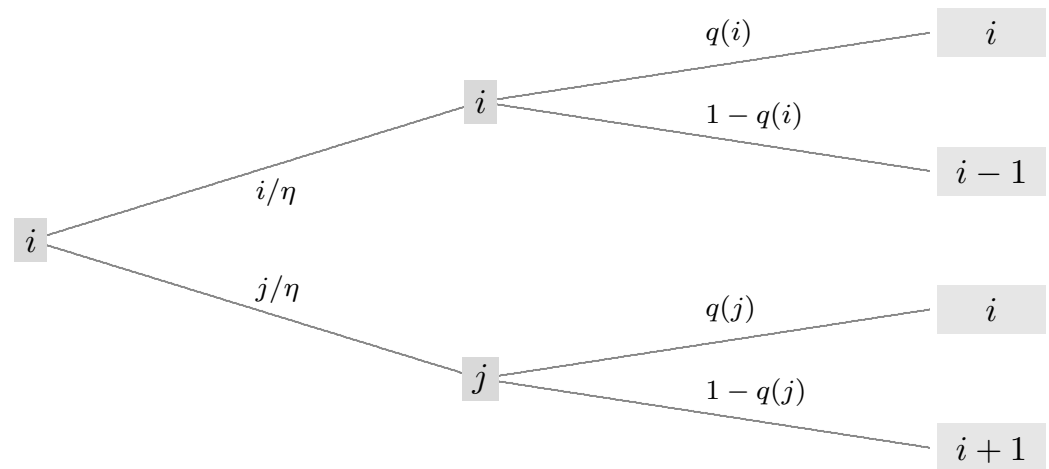

Active consumer makes choice. Period payoffs are paid.

\begin{tabular}{|c|c|c|}
\hline $\begin{array}{l}\text { Nature selects } \\
\text { "active" consumer }\end{array}$ & \multicolumn{2}{|c|}{$\begin{array}{c}\text { makes choice. Period } \\
\text { payoffs are paid. }\end{array}$} \\
\hline $\begin{array}{c}\text { Initial state. Firms } \\
\text { set prices }\end{array}$ & $\begin{array}{c}\text { Nature generates } \\
\text { active consumer's } \\
\text { preference }\end{array}$ & New state \\
\hline
\end{tabular}

I will focus on symmetric Markov equilibria, which are characterized by a pricing strategy $p(i)$, where $i$ is the number of living consumers who have purchased from firm $i$. In the remainder of the section, I first derive the determinants of consumer demand. Next, I derive the firm value functions and the resulting pricing strategy. Putting together demand and pricing, I derive a master equation that determines the evolution of market shares. The section concludes with two preliminary results: one regarding equilibrium existence and uniqueness; and another one regarding the stationary distribution of market shares.

- Consumer demand. At state $i$, an active consumer chooses firm $i$ if and only if,

$$
\zeta_{i}-p(i)>\zeta_{j}-p(j)
$$

or simply

$$
\xi_{i} \equiv \zeta_{i}-\zeta_{j}>x(i)
$$

where

$$
x(i) \equiv p(i)-p(j)
$$

Firm $i$ 's demand function is simply given by

$$
q(i)=1-\Phi(x(i))
$$

Notice that

$$
\frac{\partial q(i)}{\partial p(i)}=-\phi(x(i))
$$


- Pricing. Suppose that firms' costs are zero. Firm $i$ 's value function is then given by

$$
\begin{aligned}
v(i)= & q(i) p(i) \\
& +\frac{i}{\eta}(q(i)(\theta \Delta(i)+\delta v(i))+(1-q(i))(\theta \Delta(i-1)+\delta v(i-1))) \\
& +\frac{j}{\eta}(q(i)(\theta \Delta(i+1)+\delta v(i+1))+(1-q(i))(\theta \Delta(i)+\delta v(i)))
\end{aligned}
$$

where $i=0, \ldots, \eta$ and $j=\eta-i .^{7}$ The various terms in (5) correspond to various possibilities regarding consumer "death" and "birth." Suppose for example that the active consumer is a firm $j$ consumer, something that happens with probability $j / \eta$. Suppose moreover that this consumer chooses firm $i$, which happens with probability $q(i)$. Then firm $i$ receives sales revenue $p(i)$ (first row), current extra payoff $\theta \Delta(i+1)$, and continuation payoff $\delta v(i+1)$ (the first terms in the third row). ${ }^{8}$

Note that, with some abuse of notation, (5) corresponds both to firm i's Bellman equation and the recursive system that determines the value function. As a Bellman equation, the $v(\cdot)$ on the right hand side should be treated as $v_{c}(i)$, that is, continuation values. This is important when deriving first-order conditions, to the extent that the terms on the right-hand side should be treated as constant is the firm's optimization problem.

Define

$$
w(i) \equiv \theta(\Delta(i+1)-\Delta(i))+\delta(v(i+1)-v(i))
$$

In words, this denotes firm $i$ 's value from poaching a customer from firm $j$. This is divided into two different components: the immediate value in terms of market leadership, $\theta \Delta(i+1)$ if firm $i$ makes the sale, minus $\theta \Delta(i)$ if it does not; and the discounted future value, $\delta v(i+1)$ if firm $i$ makes the sale, minus $\delta v(i)$ if it does not.

Using (6), the first order condition for maximizing the right-hand side of (5) with respect to $p(i)$ is given by

$$
q(i)+\frac{\partial q(i)}{\partial p(i)} p(i)+\frac{i}{\eta} \frac{\partial q(i)}{\partial p(i)} w(i-1)+\frac{j}{\eta} \frac{\partial q(i)}{\partial p(i)} w(i)=0
$$

or simply

$$
p(i)=\frac{1-\Phi(x(i))}{\phi(x(i))}-\frac{i}{\eta} w(i-1)-\frac{j}{\eta} w(i)
$$

where I substitute (3) for $q(i)$ and (4) for $\partial q(i) / \partial p(i)$.

If $\theta=0$ then there are no \#1 effects: $v(i)=v(i+1), w(i-1)=w(i)=0$, and we have a standard static product differentiation model. Specifically, only the first term on the right-hand side of $(7)$ matters, where $x(i)=p(i)-p(j)$. By contrast, if $\theta>0$, then $w(i) \neq 0$ and firms lower their price to the extent of what they have to gain from making the next sale, which is given by $i / \eta w(i-1)+j / \eta w(i)$ : From firm $i$ 's perspective, with

7. Notice that, for the extreme case $i=0,(5)$ calls for values of $v(\cdot)$ which are not defined. However, these values are multiplied by zero.

8. The reason why the index in the various components differ $-i$ for $p(i)$ and $i+1$ for $\theta \Delta(i+1)$ and $v(i+1)$ - is that strategy $p(i)$ is defined over the initial state, $i$, whereas payoff $\theta \Delta\left(i^{\prime}\right)$ and continuation value $v\left(i^{\prime}\right)$ are defined over the new state $i^{\prime}$ resulting from the current active consumer's decision. 
probability $i / \eta$, the next sale is a battle for keeping one of its customers, that is, it's the difference between the continuation value of state $i$ and the continuation value of state $i-1$. With probability $j / \eta$, the next sale is a battle for attracting a rival customer, that is, it's the difference between the continuation value of state $i+1$ and the continuation value of state $i$.

Plugging this back into the value function (5) yields

$$
v(i)=\frac{(1-\Phi(x(i)))^{2}}{\phi(x(i))}+\frac{i}{\eta}(\theta \Delta(i-1)+\delta v(i-1))+\frac{j}{\eta}(\theta \Delta(i)+\delta v(i))
$$

Under static oligopolistic we would only have the first term on the right-hand side. The additional terms suggest that a firm's value corresponds to the value in case it loses the challenge for the next consumer: either losing the battle for keeping one of its consumers (a battle that takes place with probability $i / \eta$ ); or losing the battle for capturing one of the rival's consumers (a battle that takes place with probability $j / \eta$ ). This is the intuition underlying the Bertrand paradox (also known as the Bertrand trap; see Cabral and VillasBoas, 2005): to the extent that firms lower their price by the value of winning a sale, their expected value is the value corresponding to losing the sale (zero in the standard symmetric Bertrand model, the first term on the right-hand side if there is product differentiation). In other words, price competition implies rent dissipation, in the present case the $w(i)$ rent.

System (8) can be solved sequentially:

$$
v(i)=\left(1-\frac{j}{\eta} \delta\right)^{-1}\left(\frac{(1-\Phi(x(i)))^{2}}{\phi(x(i))}+\frac{i}{\eta}(\theta \Delta(i-1)+\delta v(i-1))+\frac{j}{\eta} \theta \Delta(i)\right)
$$

Finally, I will also be interested in distinguishing firm value (the function that firm decision makers maximize) from shareholder value (the firm's financial gain). The latter is given by

$$
\begin{aligned}
s(i)= & q(i) p(i) \\
& +\frac{i}{\eta}(q(i) \delta s(i)+(1-q(i)) \delta s(i-1)) \\
& +\frac{j}{\eta}(q(i) \delta s(i+1)+(1-q(i)) \delta s(i))
\end{aligned}
$$

In other words, (10) corresponds to (5) with the difference that it excludes \#1 effects, that is, $\theta=0$.

Market shares. Recalling that $x(i)=p(i)-p(j)$ and subtracting (7) from the corresponding $p(j)$ equation, we get

$$
\begin{aligned}
p(i)-p(j)= & \frac{1-\Phi(x(i))}{\phi(x(i))}-\frac{i}{\eta} w(i-1)-\frac{j}{\eta} w(i) \\
& -\frac{1-\Phi(x(j))}{\phi(x(j))}+\frac{j}{\eta} w(j-1)+\frac{i}{\eta} w(j)
\end{aligned}
$$


or simply

$$
x(i)=\frac{1-2 \Phi(x(i))}{\phi(x(i))}-\frac{i}{\eta}(w(i-1)-w(j))-\frac{j}{\eta}(w(i)-w(j-1))
$$

where I use the fact that $1-\Phi(x(j))=\Phi(x(i))$.

Equation (12) is the "master equation" determining the evolution of market shares (in expected value). Recall that $q(i)=1-\Phi(x(i))$, so a higher $x(i)$ implies a lower probability that firm $i$ makes the next sale. If $\theta=0$, so that $w(i)=0$ for all $i$, then we have a standard static product differentiation model: all terms on the right-hand side except the first one are zero and as a result $x(i)=0$ too: each firm makes a sale with the same probability.

More generally, what factors influence the value of $x(i)$ ? Essentially, the difference across firms in the value of winning the sale: as shown before, firms lower their prices to the extent of their incremental value of winning a sale; the firm that has the most to win will be the most aggressive, thus increasing the likelihood of a sale. The value of winning a sale may be decomposed into (a) the immediate benefit from an increment in market share, $\theta \Delta(i+1)-\theta \Delta(i)$ or $\theta \Delta(i)-\theta \Delta(i-1)$ as the case may be; and (b) the discounted future value from market share, $v(i+1)-v(i)$ or $v(i)-v(i-1)$, as the case may be.

- Equilibrium. Equations (9) and (12) define a Markov equilibrium, where I note that $w(i)$ is given by (6). Given the values of $v(i)$ and $x(i)$, prices $p(i)$ and sales probabilities $q(i)$ are given by (7) and (3), respectively. Many of the results in the next sections pertain to the limit case when $\delta \rightarrow 0$. These results are based on the following existence and uniqueness result:

Lemma 1. There exists a unique equilibrium in the neighborhood of $\delta=0$. Moreover, equilibrium values are continuous in $\delta$.

The proof of this and subsequent results may be found in the Appendix.

Stationary distribution of market shares. Given the assumption that $\Phi(\cdot)$ has full support (part (iii) of Assumption 1), $q(i) \in(0,1) \forall i$, that is, there are no corner solutions in the pricing stage. It follows that the Markov process of market shares is ergodic and I can compute the stationary distribution over states. This is given by the (transposed) vector $m$ that solves $m M=m$. Since the process is question is a "birth-and-death" process, whereby the state only moves to adjacent states, I can directly compute the stationary distribution of market shares:

Lemma 2. The stationary distribution $m(i)$ is recursively determined by

$$
m(i)=m(0) \prod_{k=1}^{i} \frac{q(i-1)}{1-q(i)} \cdot \frac{\eta-i+1}{i}
$$

where

$$
m(0)=\left(1+\sum_{i=1}^{\eta} \prod_{k=1}^{i} \frac{q(i-1)}{1-q(i)} \cdot \frac{\eta-i+1}{i}\right)^{-1}
$$


Lemmas 1 and 2 allow for a partial analytical characterization of equilibrium. I will develop two types of analytical results: one corresponds to taking limits as $\delta \rightarrow 0$; the second, to taking derivatives with respect to $\delta$ at $\delta=0$ (that is, linearizing the model). I complement these analytical results with numerical simulations for higher values of $\delta$. These numerical simulations confirm the analytical results for small $\delta$ but also uncover additional features not present in the small $\delta$ case.

\section{A theory of price wars}

I cannot find a general analytical closed form solution for the model's equilibrium. However, I can characterize the equilibrium when $\delta=0$; and, by Lemma 1 , in the neighborhood of $\delta=0$ the equilibrium values take on values close to the limit case $\delta=0$. In the following results, I assume for simplicity that $\eta$ is even, and I denote the symmetric state by $i^{*} \equiv \eta / 2$.

Proposition 1. There exists a unique equilibrium in the neighborhood of $\delta=0$. Moreover,

$$
\begin{aligned}
& \lim _{\delta \rightarrow 0} p(i)= \begin{cases}\frac{1}{2 \phi(0)}-\theta & \text { if } i=i^{*} \\
\frac{1}{2 \phi(0)}-\frac{\eta+1}{\eta} \theta & \text { if } i=i^{*} \pm 1 \\
\frac{1}{2 \phi(0)} & \text { otherwise }\end{cases} \\
& \lim _{\delta \rightarrow 0} q(i)=\frac{1}{2} \\
& \lim _{\delta \rightarrow 0} v(i)= \begin{cases}\frac{1}{4 \phi(0)}-\theta & \text { if } i \leq i^{*}-1 \\
\frac{1}{4 \phi(0)}-\frac{i^{*}-1}{\eta} \theta & \text { if } i=i^{*} \\
\frac{1}{4 \phi(0)}+\frac{i^{*}-1}{\eta} \theta & \text { if } i=i^{*}+1 \\
\frac{1}{4 \phi(0)}+\theta & \text { if } i \geq i^{*}+2\end{cases} \\
& \lim _{\delta \rightarrow 0} m(i)=\frac{\eta !}{i !(\eta-i) ! 2^{\eta}}
\end{aligned}
$$

The limiting stationary distribution is maximal at $i^{*}$.

In words, when firm market shares are close to each other, firms engage in a price war for market leadership, whereby both firms decrease price by up to $\theta$ from the static Hotelling price level $\frac{1}{2 \phi(0)}$. This is similar to the idea underlying the Bertrand paradox: the potential gain from being a market leader is competed away through pricing. Specifically, I define the "price war region" of the state space as the set $\left\{i^{*}-1, i^{*}, i^{*}+1\right\}$. Proposition 1 then states that, in the limit as $\delta \rightarrow 0$, prices are set lower than $\frac{1}{2 \phi(0)}$ (price war) when $i \in\left\{i^{*}-1, i^{*}, i^{*}+1\right\}$; and are equal to $\frac{1}{2 \phi(0)}$ (peace) when $i \notin\left\{i^{*}-1, i^{*}, i^{*}+1\right\}$.

Note that, in the limit as $\delta \rightarrow 0, p(i)=p(j)$. As a result, the probability of making a sale is uniform at $\frac{1}{2}$. This implies that market share dynamics follow a straightforward reversion to the mean process: smaller firms increase their market share on average, whereas larger firms decrease their market share on average. This is particularly bad for profits because it implies a constant tendency to engage in a price war. 


\section{Figure 2}

Equilibrium when $\theta=1$ and $\delta=0$ (lighter lines) and $\delta=0.9$ (darker lines).
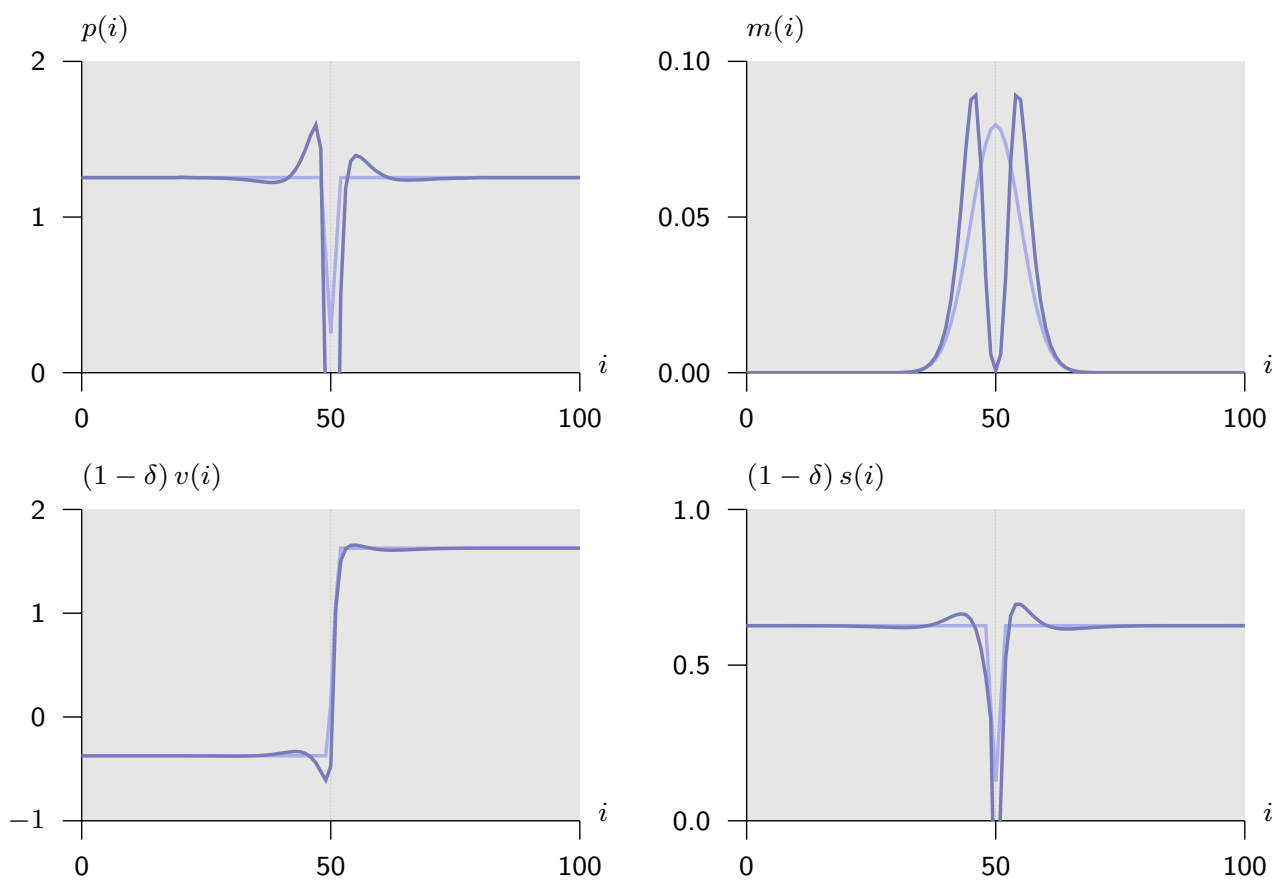

The lighter lines in Figure 2 illustrate this situation. (In this and in the remaining figures in the paper, I assume $\eta=100$, so that $i$ is both the state and firm $i$ 's market share. ${ }^{9} \mathrm{I}$ also assume that $\xi$ is distributed according to a standardized normal. ${ }^{10}$ ) The top left panel depicts the equilibrium price function, whereas the top right panel shows the stationary distribution of market shares. (Note that, since the equilibrium is symmetric, $p(i)$ and $m(i)$ are only a function of the state, not of the firm's identity.) The bottom panels show the value functions for firm managers (left) and shareholders (right).

Beginning with the price mapping, we see that prices are set at a constant level (the static equilibrium level) when the state is outside the price war region. Inside the price war region, firm prices drop by up to $\theta$, which is the change in firm value from moving up one unit in the state space. Since the price mapping is symmetric about $i^{*}$, each firm's sale probability is flat at $\frac{1}{2}$. It follows that the stationary distribution of market shares is a simple multinomial centered around $i^{*}$ (that is, around $50 \%$ market share).

The bottom right panel shows that shareholder value drops sharply when $i$ is near $i^{*}$, that is, in the price war region. This follows form the fact that prices are lower near the symmetric state and also the fact that shareholders do not receive any benefit from being \#1. In other words, since shareholders do not care for market leadership per se, \#1 effects are only bad news: they lead to price wars, which in turn destroy shareholder value.

9. The qualitative features of the results remain the same for different values of $\eta$. However, in the limit when $\eta \rightarrow \infty$, aggregate noise vanishes and the model becomes deterministic.

10. The assumption that $\xi$ follows a standardized normal implies no additional loss of generality with respect to $\xi$ being normal, on account of my symmetry assumption and an appropriate change of units. 
With respect to firm value, the bottom left panel indicates that, in the limit as $\delta \rightarrow 1$, $v(i)$ is increasing in $i$. In particular, if $i>i$ star then firm $i$ receives utility $\theta$ in addition to expected revenues. This benefit from leadership is balanced out by the negative utility suffered by the laggard.

Finally, although not obvious from Figure 2, industry joint value, $v(i)+v(j)$, at states near $i^{*}$ is actually lower when $\theta>0$ than when $\theta=0$. This follows from Proposition 1 , as the next result attests:

Corollary 1. In the limit as $\delta \rightarrow 0$, joint industry value $v(i)+v(j)$ is strictly decreasing in $\theta$ if $i \in\left\{i^{*}-1, i^{*}, i^{*}+1\right\}$, constant otherwise.

This is an important point, one that warrants further elaboration. The idea is akin to the Bertrand paradox. In a first-price auction where the payoff from winning is given by $+\pi$ and the payoff from losing is given by $-\pi$, the greater the value of $\pi$, the lower the equilibrium value by both bidders: the winner gets $\pi$ from winning minus $2 \pi$, the equilibrium bid; whereas the loser gets $-\pi$. In the present context, an increase in $\theta$ increases the payoff from winning a sale and decreases the payoff of losing it. Although the total payoff from market leadership is constant (specifically, $\theta \Delta(i)+\theta \Delta(j)=0$ ), the equilibrium value received by each firm is decreasing in $\theta$ : in equilibrium, each firm fares as well as when it loses the sale. $^{11}$

An additional implication of Proposition 1, similar to Corollary 1, is that industry joint value is higher at asymmetric states than at symmetric states, so that, at symmetric or near-symmetric states, the leader has more to gain from increasing its lead that the laggard has to lose from falling farther behind.

Corollary 2. At $\delta=0, v(i)+v(j)$ is strictly increasing in $|i-j|$ if $|i-j| \leq 2$. Moreover,

$$
\begin{aligned}
v\left(i^{*}+1\right)-v\left(i^{*}\right) & >v\left(i^{*}\right)-v\left(i^{*}-1\right) \\
v\left(i^{*}+2\right)-v\left(i^{*}+1\right) & >v\left(i^{*}-1\right)-v\left(i^{*}-2\right)
\end{aligned}
$$

In words, the second part of Corollary 2 states that, at state $i^{*}+1$, what the leader has to lose by moving down on step is more than what the laggard has to gain by moving up one step; and what the leader has to gain by moving up one step is more than what the laggard has to lose by moving down one step. This is the dynamic equivalent of Gilbert and Newbery's (1982) "efficiency effect." In their paper, it results from the convexity of the profit function; in my paper, it results from the convexity of the value function. ${ }^{12}$

Notice that the two parts of Corollary 2 are equivalent: both stem from the the value function being "convex." In fact, $v\left(i^{*}+1\right)-v\left(i^{*}\right)>v\left(i^{*}\right)-v\left(i^{*}-1\right)$ is equivalent to $v\left(i^{*}+1\right)+v\left(i^{*}-1\right)>v\left(i^{*}\right)+v\left(i^{*}\right)$; and $v\left(i^{*}+2\right)-v\left(i^{*}+1\right)>v\left(i^{*}-1\right)-v\left(i^{*}-2\right)$ is equivalent to $v\left(i^{*}+2\right)+v\left(i^{*}-2\right)>v\left(i^{*}-1\right)+v\left(i^{*}+1\right)$. In words, if the value function is convex, then its "slope" is greater for the leader than for the laggard. Similarly, by a

11. Cabral and Villas-Boas (2005) denote by Bertrand super trap the situation (as is the present case) when the strategic effect of an exogenous change is greater in absolute value and opposite in sign to the direct effect.

12. The joint value effect corresponds vaguely to the principle of least action in classical mechanics; dynamic pricing implies that, in expected terms, the state space moves in the direction that joint value is maximized. 


\section{Figure 3}

Market leadership benefit (left) and value function (right) at $\delta=0$ for $\theta=0$ (light lines) and $\theta>0$ (dark lines), where $i^{*}$ is the symmetric state.
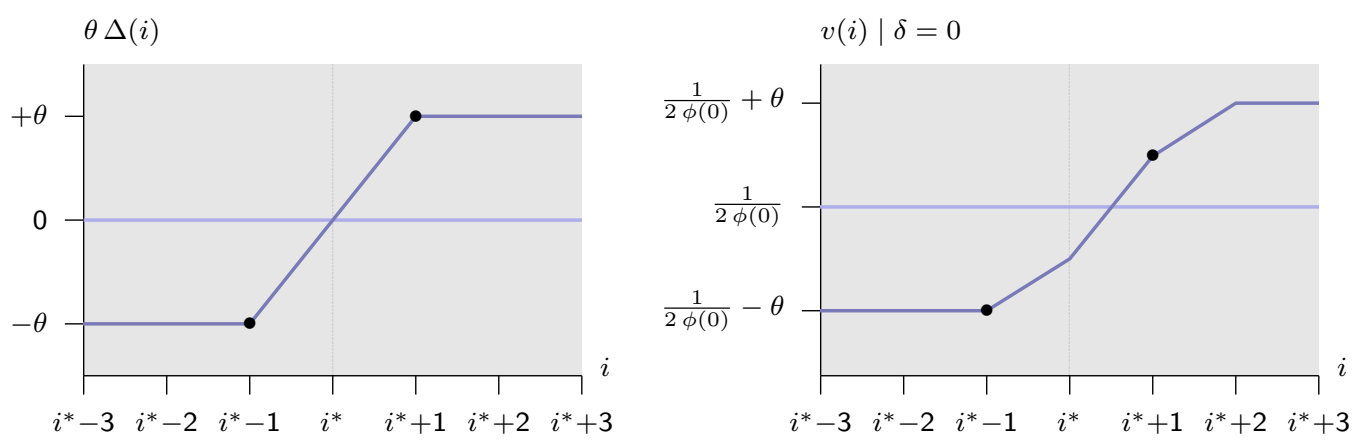

discrete analog of Jensen's inequality, joint profit increases when the state becomes more asymmetric.

Figure 3 illustrates Corollaries 1 and 2. The left-hand panel depicts the market leadership mapping. As can be seen, the mapping is symmetric about $\left(i^{*}, 0\right)$, so that the sum $\Delta(i)+\Delta(j)$ is equal to zero at every state. The same is not true, however, regarding value functions, as can be seen from the right-hand panel. For example, at state $i^{*}$, each firm's payoff when $\theta>0$ is lower than it would be if $\theta=0$ (Corollary 1). Moreover, $v(i)$ is "convex". At $i=i^{*}$, this corresponds to the fact that $v\left(i^{*}\right)-v\left(i^{*}-1\right)<v\left(i^{*}+1\right)-v\left(i^{*}\right)$; at $i=i^{*}-1$, it corresponds to the additional fact that $v\left(i^{*}+2\right)-v\left(i^{*}+1\right)>v\left(i^{*}-1\right)-v\left(i^{*}-2\right)$ (Corollary 2).

Corollaries 1 and 2 have important implications for system dynamic in the neighborhood of $\delta=0$, as I will show next.

- Positive, small values of $\delta$. Proposition 1 considers the limit when $\delta \rightarrow 0$. From Lemma 1 , I know that the system's behavior is continuous around $\delta=0$, that is, the limit $\delta \rightarrow 0$ is a good indication of what happens for low values of $\delta$. Additional information can be obtained by linearizing the system around $\delta=0$ and thus determining the direction in which equilibrium values change as $\delta$ moves away from zero. ${ }^{13}$

Recall that, in the limit as $\delta \rightarrow 0, p(i)=p(j)$ and $q(i)=q(j)$. My next result shows that, in the near symmetric states $i^{*}-1$ and $i^{*}+1$, the market leader sets a low price and sells with higher probability. Moreover, the laggard is strictly worse off by increasing its market share.

Proposition 2. There exists a $\delta^{\prime}>0$ such that, if $0<\delta \leq \delta^{\prime}$, then $\theta>0$ implies

$$
\begin{aligned}
& p\left(i^{*}+1\right)<p\left(i^{*}-1\right) \\
& q\left(i^{*}+1\right)>q\left(i^{*}-1\right) \\
& v\left(i^{*}-1\right)<v\left(i^{*}-2\right)
\end{aligned}
$$

(Notice that, given the demand curve (3), the first two inequalities are equivalent.)

13. This is similar to the approach followed by Budd, Harris and Vickers (1993) and Cabral and Riordan (1994). 
As mentioned earlier — and as shown by (7) - firm $i$ 's first-order condition includes the value of winning a sale, either the value of keeping an existing customer, $w(i-1)$, or the value of poaching a rival's customer, $w(i)$. When $\delta=0$, the value of winning a customer is based on the mapping $\theta \Delta(i)$, as illustrated in the left-panel of Figure 3. Consider for example a firm with $i^{*}-1$ customers. If this firm gains one customer, its payoff increases by $\theta$, whereas its rival, by moving from $i^{*}+1$ to $i^{*}$, decreases by $\theta$. Conversely, if the firm at $i^{*}-1$ loses one customer, then its leadership payoff remains the same, whereas its rival, by moving from $i^{*}+1$ to $i^{*}+2$, also sees its payoff remain constant. In sum, for $\delta=0$, what the leader has to gain (reap. lose) from making a sale is the same as the laggard has to lose (reap. gain). As a result, both firms apply the same "subsidy" to their price level and $q(i)=1 / 2$ for all $i$, as stated in Proposition 1 .

Consider now the case when $\delta$ is positive but infinitesimal. Given that the active consumer is a $j$ consumer, firm $i$ 's value from winning a sale is given by $w(i) \equiv \theta \Delta(i+1)-$ $\theta \Delta(i)+\delta v(i+1)-\delta v(i)$. At $\delta=0$, as we have seen, the values of $w(i)$ for leader and laggard balance out exactly. As we increase $\delta$ infinitesimally, the value of $w(i)$ increases at the rate $v(i+1)-v(i)$, where the value functions are evaluated at $\delta=0$. Proposition 2 exploits the fact that, while the values of $\theta \Delta(i)$ add up to a constant, so that leader and laggard have the same to win or lose, the same is not true for $v(i+1)-v(i)$, as Corollary 2 states.

Specifically, consider the near-symmetric sate $\left(i^{*}-1, i^{*}+1\right)$. As Corollary 2 shows, the lagging firm has less to gain from moving up the value function than the laggard has to lose from losing to the laggard. Moreover, the laggard has less to lose from falling farther behind than the leader has to gain from moving further ahead. In other words, the value function is "convex." Given the intuition underlying the first-order conditions (7), this implies that the leader prices more aggressively, which results in it making a sale with a higher probability than the laggard.

- Higher values of $\delta$. For high values of $\delta$, I cannot find a closed-form analytical solution or linear expansion approximation. However, I can solve the model numerically. The dark lines in Figure 2 show the model's solution for $\delta=0.9$. The solution looks qualitatively similar to $\delta=0$ in various respects, namely in the property that prices drop when firms market shares are close to each other. However, upon closer inspection important differences become apparent as well. First, as suggested by Proposition 2, when $\delta>0$ the pricing function is no longer symmetric about $i^{*}$. In particular, just outside the price war region, the large firm's price is lower, whereas the smaller firm's price is higher. This implies that the probability of a sale by a leader increases when the leader's market share drops to close to $i^{*}$. As the top right panel in Figure 2 shows, this (may) imply that the stationary distribution of market shares be bi-modal. ${ }^{14}$ That is, most of the time the system lies at an asymmetric state, where one firms is larger and the other firm smaller.

- Price and market share dynamics. Proposition 1 shows that firms engage in price wars when the state space is close to the symmetric state, whereas Proposition 2 suggests that market shares tend to remain stable around asymmetric outcomes. I now examine the implications of these properties. Figure 4 illustrates the dynamics of price and market shares

14. Simulations show that this requires the value of $\delta$ to be sufficiently high. In fact, all curves vary smoothly with $\delta$, and for $\delta=0$ the stationary distribution is uni-modal, as we saw earlier. 


\section{Figure 4}

Price and market share dynamics $(\delta=0.9, \theta=1)$

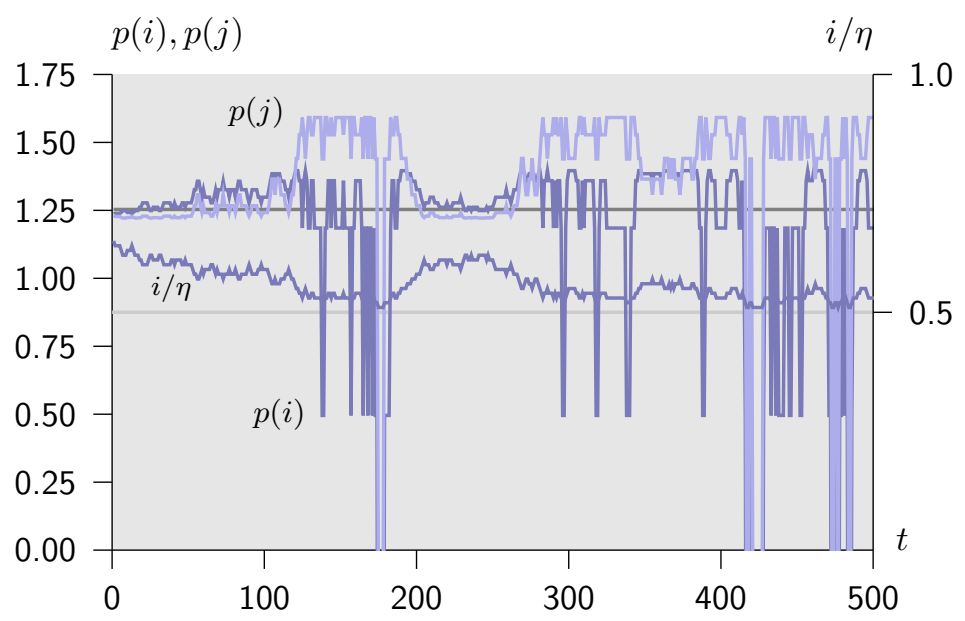

by showing the results of a model simulation when $\delta=0.9$ and $\theta=1$ (the parameter values corresponding to Figure 2). ${ }^{15}$ The dark lines represents firm $i$ 's price and market share; and the light line, firm $j$ 's price. Two horizontal lines are also included: the lighter line marks the value of $i^{*}$ (right scale), whereas the darker line corresponds to the equilibrium price when $\theta=0 .{ }^{16}$

According to my model, a price war is a period of significantly lower prices that takes place when the firms' market shares are close enough (if $\delta=0$, when $|i-j| \leq 2$ ). As can be seen in Figure 4, price wars take place when the leader's market share drops to close to $50 \%$. When that happens, firm $i$ has a lot to lose from further lowering its market share, whereas firm $j$ also increases the value from winning additional customers. This shifts both firms' first-order conditions and causes them to lower prices. To the extent that $\delta$ and $\theta$ are high, firm $i$ will "normally" prevail and its market share reverts to a high level, thus re-establishing pricing "peace." In the long-run, the system spends most of the time at asymmetric states, with well-defined large and small firms.

My paper is by no means the first papers to features a symmetric equilibria with asymmetric outcomes and price wars near symmetry states. Besanko, Doraszelski, Krykov and Sattertwaite (2010), for example, show that learning curves lead to "trenchy" price equilibria whereby prices drop when competitors' market shares are close to each other. ${ }^{17} \mathrm{My}$ model differs from the previous literature in that it does not feature increasing returns to scale. In fact, by construction, $\theta \Delta(i)+\theta \Delta(j)$ is equal to zero. Specifically, if prices were set at a constant level, my model would imply that industry joint value $v(i)+v(j)$ is constant across states, whereas Besanko, Doraszelski, Kryukov and Satterthwaite (2010) or Cabral (2011), for example, would imply that $v(i)+v(j)$ is increasing in $|i-j|$.

Moreover, while the stationary distribution of market shares is multi-modal, it still places significant mass on symmetric or near-symmetric states. (If $\delta=0$, the stationary distribution of market shares is a binomial centered around 50\%.) As a result, price wars

15. The simulation starts with $i=60$ and is based on a random seed equal to 1 .

16. Specifically, $\theta=0 \Rightarrow p(i)=1 / \phi(0)=1.2533$, given my assumption that $\xi \sim N(0,1)$.

17. In fact, I adapt the term "trenchy" from Besanko, Doraszelski, Kryukov and Satterthwaite (2010). 
are relatively frequent, whereas in models with increasing returns to scale they are rare: once one of the firms becomes dominant, it takes a long time for tipping to take place. This is an important distinction, one that warrants further discussion. In dynamic market share models there is a natural force of reversion to the mean: consumer death. A firm with $100 \%$ of the market can only decrease its market share. Against this force pushing towards market share balance, there may be various forces pushing the system away from symmetry. Increasing returns (learning curves or network effects) represent one such force. In my model, the force that pushes away from symmetry is price wars. However, to the extent that price wars only kick in at states close to symmetry, its effect is only felt at states close to symmetry. As a result, we have a stationary distribution where much of the weight is at states close to the threshold of the price war region. This results in frequent movements inside the price war region. In other words, unlike models with increasing returns, price wars are observed cyclically along the equilibrium path. In Section 4 I return to this issue.

- Competition policy implications. One of the central issues in competition policy is the distinction between competitive and collusive market behavior. Absent hard evidence of price fixing, one possibility is to infer from market data whether there are observable signs consistent with collusion. Specifically, Harrington (2008), derives a series of "collusive markers," that is, screens that help identify the presence of collusive behavior. One such marker is that "price and quantity can be subject to large and persistent changes in the absence of large demand and cost changes." Similarly, Kaplow (2013) observes that

Oligopolists rely on the feasibility of price wars in order to establish and maintain supra-competitive prices in the first place ... Sudden, sharp price reductions are as suspicious as sudden, sharp price increases ... in the absence of corresponding changes in cost or demand.

He goes on to conclude that "if enforcement makes price wars difficult, oligopoly pricing may be discouraged after all."

There is an extensive theoretical literature that provides a foundation for this perspective on price wars. Consider for example the analysis in Fershtman and Pakes (2000), who develop a dynamic oligopoly model with entry and exit. They contrast a collusive with a competitive equilibrium and show that only the collusive equilibrium generates price wars. More generally, the textbook treatment of price wars is very closely linked to collusion theory (Green and Porter, 1982; Rotemberg and Saloner, 1987).

In contrast with this conventional wisdom, the equilibrium I described earlier features very drastic changes in price (price wars) as a result of relatively minor changes in demand - and corresponds to no collusive behavior, rather fairly aggressive pricing behavior.

A second collusive marker considered by Harrington (2008) is that "under certain conditions firms' prices are more strongly positively correlated under collusion." In fact, Macleod (1985) and Harrington (2012) provide formal frameworks in which parallel pricing forms part of a collusive equilibrium. However, my analysis shows that parallel pricing may also result from a competitive equilibrium.

Before developing his list of collusive markers, Harrington (2008) is careful enough to disclaim that "evidence supporting collusion need not imply evidence against competition." My analysis reinforces this point by showing that an equilibrium with regime changes and parallel price variations is perfectly consistent with competitive market behavior. 
- Shareholder value. The bottom right panel in Figure 2 shows an additional important difference between the equilibrium with $\delta=0$ and the equilibrium with $\delta=0.9$. In the former case, \#1 effects are unambiguously detrimental to shareholder value. This is fairly intuitive: \#1 effects lead firms (symmetrically) to lower prices when in state $i \in\left\{i^{*}-1, i^{*}, i^{*}+1\right\}$. Lower prices lower shareholder value; moreover, \#1 effects accrue no shareholder utility. All in all, wanting to be \#1 is bad for shareholders.

However, if $\delta$ is sufficiently high (e.g., $\delta=0.9$ ), then there are states when shareholder value is greater with $\theta>0$ than with $\theta=0$. In other to understand this, it helps to notice that, as shown in Proposition 2, v(i) is decreasing for values of $i$ lower than, but close to, $i^{*}$. In other words, a laggard becomes worse off as its market share approaches the leader's. The reason is that the increase in market share induces very aggressive pricing behavior by the leader, which in turn reduces the laggard's value: the laggard receives no benefit from market leadership but pays the cost of a leader eager to defend its benefit from market leadership.

As seen earlier, the first-order condition for optimal pricing includes a "subsidy" in the amount of the expected continuation gain from making a sale, either the value of keeping an own contested consumer, $w(i-1)$, or the value of poaching a consumer from the rival firm, $w(i)$. If the value function is decreasing (and the payoff from market leadership does not change), then a declining $v(i)$ implies a negative $w(i)$, which in turn implies that the price "subsidy" becomes a "tax." In other words, the "threat" of entering a price war with the leader softens the laggard. This effect may be so strong so as to increase the leader's shareholder value (in the states where the laggard softens up). In other words, even though shareholders do not care about market leadership per se, shareholder value may increase when managers care for market leadership.

Although the Markov equilibrium I consider differs greatly from a repeated game (where, by definition, there is no state space such as market share), there is an interesting similarity between the above effect and the so-called topsy-turvy principle in collusive repeated game equilibria (Shapiro, 1989). Consider a repeated game where each period one consumer buys one unit from one of two firms. Consider a class of grim-strategy equilibria whereby price is $\bar{p}$ along the equilibrium path and strategies are such that, if any player sets $p \neq \bar{p}$, then play reverts to $p$ forever (for simplicity, I ignore issues of subgame perfection or renegotiation proofness). Suppose that buyers choose the firm with the lowest price and that willingness to pay is sufficiently high that it is not binding. Then, for a given discount factor, the lower the value of $p$ is, the higher the maximum $\bar{p}$ that is sustainable as a Nash equilibrium of the repeated game.

In my model, equilibrium play moves between states in the "price war" region and outside the price war region. If we think of price war states as similar to punishment periods in the repeated game, then the corresponding topsy-turvy principle is that the deeper the price cuts in the price war region, the higher prices are once outside of the price war region. The reason is that deeper price cuts imply a bigger drop in $v(i)$ for the laggard when close to $i^{*}$ and, consequently, a higher "tax" on price.

\section{Robustness and extensions}

In this section, I develop a series of extensions to my basic framework. First, I consider the case when one of the firms unilaterally changes the value of its $\theta$ parameter, that is, 


\section{Figure 5}

Asymmetric game: $\theta_{a}=1, \theta_{b}=0\left(\delta=\frac{3}{4}\right)$.

Key: firm $a$ in dark, firm $b$ in medium shade line (light line: symmetric $\theta_{a}=\theta_{b}=0$ case).
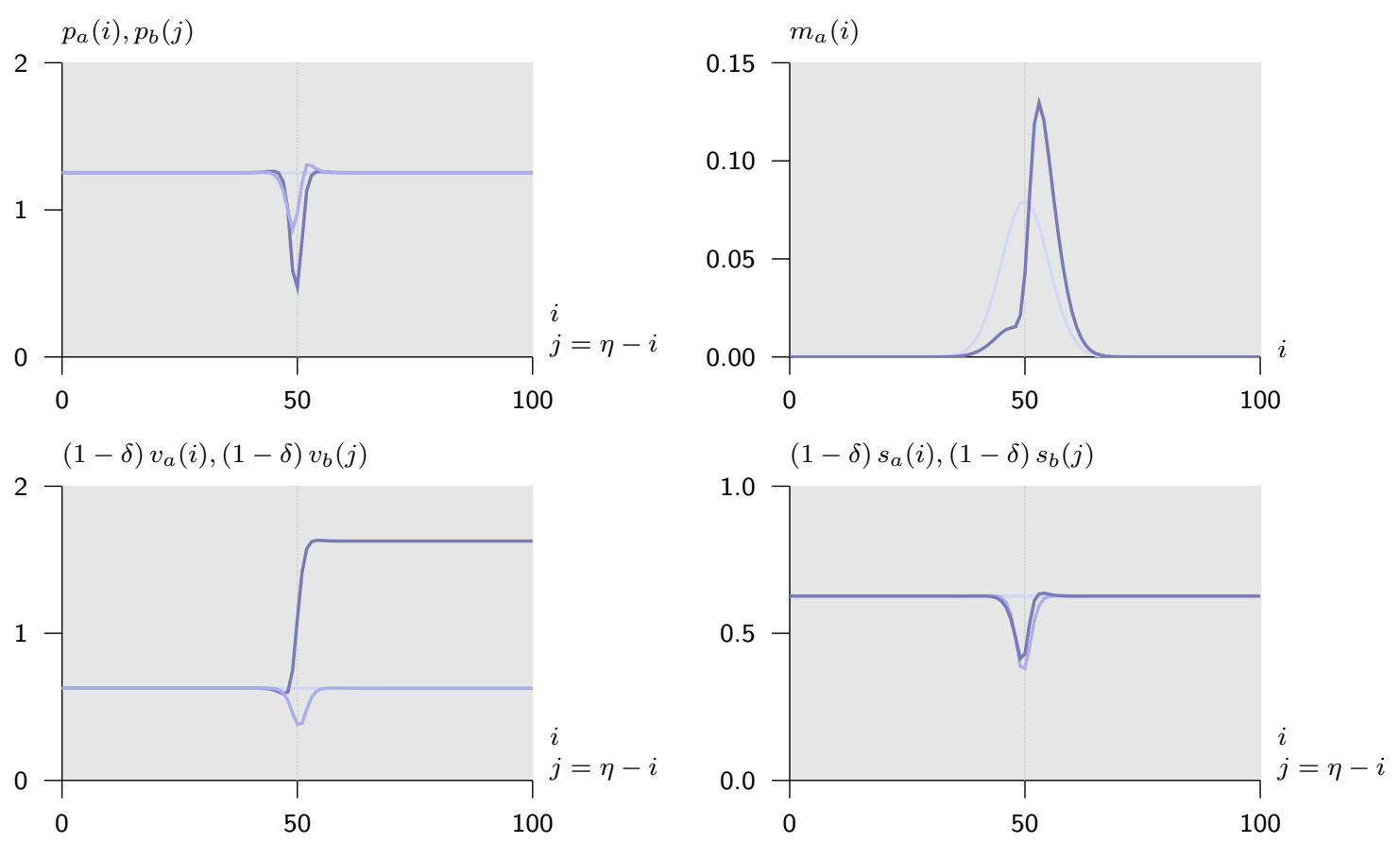

the case when one firm values market leadership whereas the other one does not. Next I consider the case when it's consumers who value purchasing from a market leader, rather than firms who enjoy being market leaders. Next I consider different mappings describing the benefit from market leadership. After that, I perform a series of comparative dynamics exercises, where various key parameter values are changed. The section concludes with the development of the case when there are more than 2 firms.

Asymmetric \#1 effects. So far I have considered the case when both firms benefit from begin market leaders. In order to consider the possibility of a firm creating its own "culture" - in the sense of how much it values market leadership — it is helpful to consider the case when the value of $\theta$ is firm specific. Figure 5 depicts the case when $\theta_{a}>0$ whereas $\theta_{b}=0$.

The qualitative features of firm $a$ 's pricing function are similar to the symmetric case: when firm $a$ 's market share is close to $50 \%$, its prices are lower as its value function is very steep. Notice that, while firm $b$ gains nothing from being the market leader, it too lowers its price when market shares are similar. This results from strategic complementarity in pricing as well as from the fact that $v_{b}(i)$ too is steeper when $i \approx i^{*}$. In particular, when firm $b$ is a market leader with a short lead, it knows that a decrease in market share implies a significant decrease in value: it implies entering a value-destroying price war with a rival who care about market share leadership. In fact, as the top left panel of Figure 5 suggests, firm $b$ leads firm $a$ in cutting prices when firm $b$ 's market share drops toward $i^{*}$ (which, in Figure 5, corresponds to an increase in $i$ toward $i^{*}$ ). 
One important difference between the symmetric and asymmetric cases is that the stationary distribution of market shares is no longer symmetric. In fact, consistent with the fact that firm $a$ places extra value on being a market leader, whereas firm $b$ does not, most of the time firm $a$ is effectively the market leader, as can be seen from the top right panel.

In the previous section, I showed that, in a symmetric equilibrium, shareholder value may be higher in some states when $\theta>0$ than when $\theta=0$ : even though shareholders do not benefit from being market leaders, they may benefit from hiring managers who benefit from being market leaders. I next present two limit results that characterize shareholder value when $\theta_{a}>0$, that is, when only one firm's manager benefits from being the market leader. The first result is a simple corollary of the asymmetric version of Proposition 1: if $\delta=0$, then the game is effectively as sequence of "static" games where future values $v_{k}(i)$ do not matter. As seen in the proof of Proposition 1, a positive $\theta_{a}$ implies lower prices in some states. Since this amounts to a deviation from the first order condition under $\theta_{a}=0$, it must decrease firm value. By continuity, we conclude that the same is true for values of $\delta$ close to zero (that is, the above inequality is strict).

At the opposite extreme, I can also find sufficient conditions such that a unilateral \#1 effect increases shareholder payoffs. Suppose that (a) the managers' discount factor is very small but the shareholders' discount factor, denoted by $\delta_{s}$, is very high; (b) in addition to the "psychological" value $\theta$, market shares have real value, that is, value that accrues to shareholders in addition to managers: specifically, firms receive a flow payoff $\psi i$ per periods, where $\psi>0 .{ }^{18}$ (Intuitively, we may think of $\psi$ as after-sales service revenues per customer.) Then I can provide conditions such that a unilateral increase in $\theta_{a}$ leads to higher shareholder value. Intuitively, by an argument similar to that of Proposition 1 and the explanation for Figure 5, a unilateral increase in $\theta_{a}$ implies a rightward shift in the stationary distribution of market shares. A very patient shareholder only cares about the stationary distribution of market shares. Finally, a small increase in $\theta_{a}$ has an infinitesimal negative impact on profitability (by the envelope theorem), whereas the shift in the stationary distribution of market shares is a first-order effect.

The next result summarizes the discussion in the preceding paragraphs.

Proposition 3. There exists a $\delta^{\prime}>0$ such that:

(a) If $0<\delta \leq \delta^{\prime}$ and $0<\delta_{s} \leq \delta^{\prime}$, then $s_{a}(i)$ is strictly decreasing in $\theta_{a}$ for $i \in\left\{i^{*}-\right.$ $\left.1, i^{*}, i^{*}+1\right\}$

(b) There exist $\psi^{\prime}, \delta^{\prime}>0$ and $\delta_{s}^{\prime}<1$ such that, if $\psi \geq \psi^{\prime}, \delta \leq \delta^{\prime}$, and $\delta_{s} \geq \delta_{s}^{\prime}$, then $s_{a}(i)$ is increasing in $\theta_{a}$.

Obviously, two can play the same game. A possible next step would to analyze the "metagame" played by firms $a$ and $b$ when each can choose $\theta_{k}$. The above results and numerical simulations suggest that the equilibrium of this meta-game may sometimes be $\theta_{a}=\theta_{b}=0$; and that it sometimes have the structure of a prisoner's dilemma, where both firms choose positive $\theta_{k}$ and both firms receive a lower equilibrium payoff than in the situation where both choose $\theta_{k}=0$.

18. Notice that I assume the market share benefit is linear. In this way, I maintain my initial assumption that industry joint payoff (aside from pricing) is constant with respect to $i$. 
- Demand driven \#1 effects. Up until now I have considered the case when managers derive extra utility from being market leaders; but an equally compelling observation is that consumers enjoy purchasing from a market leader. According to Hermann (2009),

Some companies use their world market leadership as an advertising message. For example, Wanzl, the worldwide leader for shopping carts, says, "The size of a world market leader creates security." Being the biggest, the first or the best has always been an effective advertising message.

Consumer \#1 effects may result from a rational Bayesian process (Caminal and Vives, 1996) or simply because it's less risky to buy from a market leader: as the saying goes, "no one ever got fired for buying IBM" (that is, when IBM was a clear market leader). Consistent with this view, recent research suggests that demand responds to ordinal rankings in the case of music (Sorensen, 2007), iPhone apps (Carare, 2012) and movies (Cabral and Natividad, 2013). ${ }^{19}$

I now extend the model to consider the possibility that consumers benefit from purchasing from the market leader. Specifically, I assume an additional term in consumer utility from buying from firm $i$ given by $\lambda \Delta(i)$, where $\lambda \geq 0$ and $\Delta(i)$ is defined as before, that is, $\Delta(i)=1$ if $i>j, \Delta(i)=-1$ if $i<j$, and $\Delta(i)=0$ if $i=j$.

At state $i$, an active consumer chooses firm $i$ if and only if

$$
\zeta_{i}+\lambda \Delta(i)-p(i)>\zeta_{j}+\lambda \Delta(j)-p(j)
$$

or simply

$$
\xi_{i} \equiv \zeta_{i}-\zeta_{j}>x(i)
$$

where

$$
x(i) \equiv p(i)-p(j)-\lambda \Delta(i)+\lambda \Delta(j)
$$

As before, my focus is on the equilibrium price function, as well as the resulting probability of a sale and stationary distribution of market shares. Suppose that $\theta=0$, that is, firms do not derive any special direct benefit from being the market leader.

Proposition 4. Suppose that $\theta=\psi=0$, whereas $\lambda>0$. There exists a unique equilibrium in the neighborhood of $\delta=0$. Moreover,

$$
\begin{aligned}
& \lim _{\delta \rightarrow 0} q(i)= \begin{cases}1-q^{\prime} & \text { if } i<i^{*} \\
1-q^{\prime}<q(i)<q^{\prime} & \text { if } i=i^{*} \\
q^{\prime} & \text { if } i>i^{*}\end{cases} \\
& \lim _{\delta \rightarrow 0} p(i)= \begin{cases}p^{\prime} & \text { if } i<i^{*} \\
p^{\prime}<p(i)<p^{\prime \prime} & \text { if } i=i^{*} \\
p^{\prime \prime} & \text { if } i>i^{*}\end{cases}
\end{aligned}
$$

19. At a theoretical level, Caminal and Vives (1996) provide a Bayesian foundation for an equilibrium where market shares signal quality, and thus consumers are willing to pay more for products with greater market share. However, they do not explain why there would be ordinal effects. Glenn Ellison has suggested a reason why ordinal effects may be present. Suppose that consumers have no initial information about product quality and try products sequentially (at a cost) until they find something they are happy with. To the extent that there is some correlation across consumer preferences, consumers strictly prefer to start with the leading product, thus creating an ordinal effect in market demand. 


\section{Figure 6}

Equilibrium when $\lambda=.5$ and $\delta=0$ (lighter lines) or $\delta=0.7$ (darker lines). (In both cases $\theta=0$.
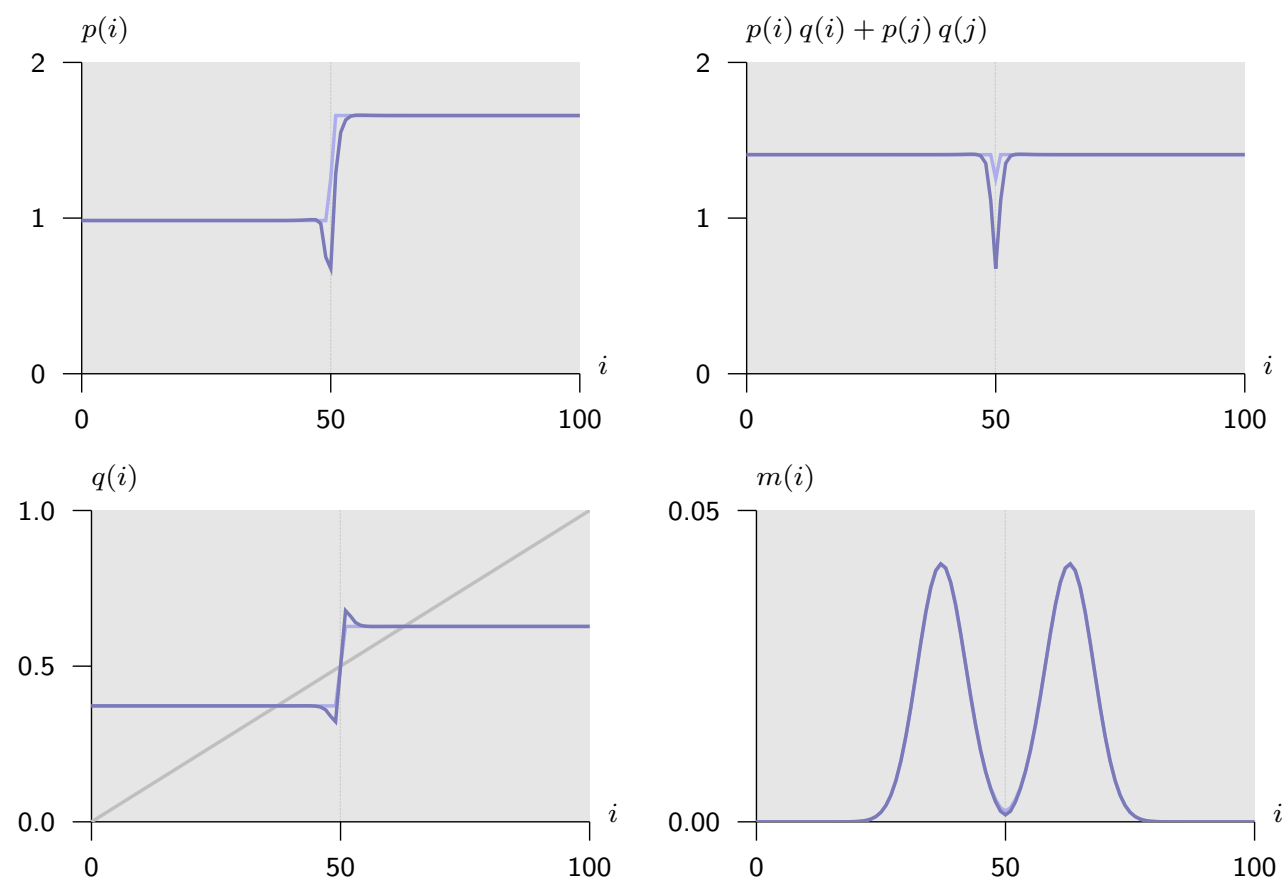

where $q^{\prime}>\frac{1}{2}$ and $p^{\prime}<\frac{1}{2 \phi(0)}<p^{\prime \prime}$. Finally, if $\lambda$ is large enough then the stationary distribution of market shares is bimodal.

Figure 6 illustrates Proposition 4. The price function no longer exhibits the "trenchy" pattern observed Proposition 1. Instead, the market leader, enjoying a preference in the eyes of the consumer, is able to price higher than the laggard. Despite a higher price, the leader sells with a higher probability than the laggard, as shown in the bottom left panel of Figure 6 . The top right panel shows that, similarly to the manager \#1 effect case, average price, that is, $p(i) q(i)+p(j) q(j)$, is lower when the state is near the symmetric state $i^{*}$.

Finally, as the bottom right panel shows, equilibrium pricing results in a bi-modal stationary distribution of market shares. The idea is that the consumer's preference for market leaders creates a self-reinforcing process whereby a leader, even if it enjoys a small lead, is able to sell with probability greater than $50 \%$ and thus cement its lead. If that lead becomes very large, then reversion to the mean dominates and the leader reduces its market share in expected terms. Together this implies a stationary distribution with modes strictly between 0 and $50 \%$ and between 50 and 100\%, respectively.

Notice finally that, since $\theta=0$, there is no divergence between the firm's and the shareholders' value: $v(i)=s(i)$. Both functions are increasing in market share: to the extent that consumers enjoy buying from the market leader, the market leader is able to set a higher price and sell with higher probability.

In sum, Proposition 4, together with Proposition 1, suggests that the effect of "the importance of being Number 1" depends on whether it's buyers or sellers who care about relative firm position. 


\section{Figure 7}

Effect on changing $\kappa$ in the generalized \#1 effect mapping. Left panel: market leadership benefit. Right panel: equilibrium price function. In both cases, lines are increasingly dark as $\kappa$ increases from 2 to 6 to 10 . Other parameter values: $\delta=.7, \theta=1$.
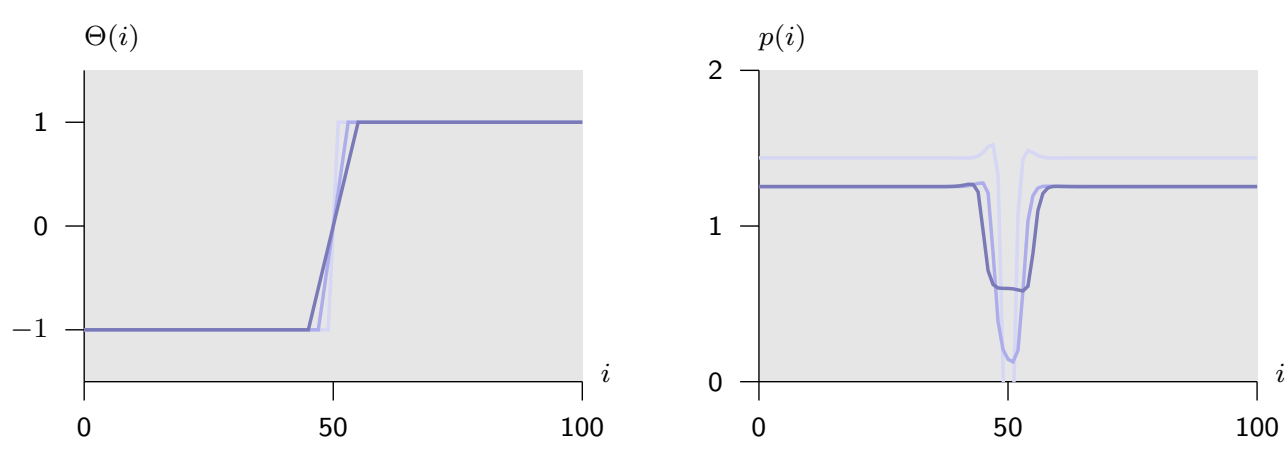

Alternative \#1 effect mappings. How much do the results in Section 3 depend on the fact that market leadership is such a "discontinuous" mapping, that is, switches from $-\theta$ when $i<j$ to $+\theta$ when $i>j$ ? In order to address this question, I consider a general mapping $\Theta(i)$ whereby the benefits from market leadership ramp up from $-\theta$ to $+\theta$ as $i$ increases from $i^{\prime}$ to $i^{\prime \prime}$, where

$$
\begin{aligned}
i^{\prime} & \equiv \frac{\eta-\kappa}{2}=i^{*}-\frac{\kappa}{2} \\
i^{\prime \prime} & \equiv \frac{\eta+\kappa}{2}=i^{*}+\frac{\kappa}{2}
\end{aligned}
$$

Note that $\kappa=i^{\prime \prime}-i^{\prime}$ measures the width of the "price war" region, that is, the region of the state space where a firm transits from being a laggard to being a leader. The generalized market leadership benefit function is then given by

$$
\Theta(i)= \begin{cases}-\theta & \text { if } i<i^{\prime} \\ \left(-1+2 \frac{i-i^{\prime}}{\kappa}\right) \theta & \text { if } i^{\prime} \leq i \leq i^{\prime \prime} \\ +\theta & \text { if } i>i^{\prime \prime}\end{cases}
$$

I will say that firm $i$ is a market leader if $i \geq i^{\prime \prime}$ and a market follower if $i \leq i^{\prime}$. The extreme $\kappa=2$ corresponds to the case when a firm is a market leader even if its market share advantage is minimal. Higher values of $\kappa$ correspond to more gradual transitions from laggard to leader.

The left panel in Figure 7 shows the $\Theta(i)$ mapping for three values of $\kappa$ (specifically, $\kappa=2,6,10)$. The right panel, in turn, shows the equilibrium pricing function for each of these values of $\kappa$. As expected, a more gradual \#1 effect mapping leads to lower price cuts that are spread over a wider region of the state space. In other words, the equilibrium pricing function is still "trenchy" but not in such a pronounced way as when $\kappa=2$. In the limit when $\kappa=\eta$, there is no "trench" at all: the benefits from being a market "leader" (which are now, really, the benefits from a high market share) lead to uniformly lower prices.

Although the mapping (15) generalizes my initial assumption regarding \#1 effects, it is still subject to kinks at $i=i^{\prime}$ and $i=i^{\prime \prime}$. However, my results are not dependent on this 


\section{Figure 8}

Comparative dynamics. Effects on equilibrium pricing of (a) $\theta=.01, .1,1$ with $\delta=.9$ (top left panel); (b) $\delta=.5, .7, .9$ with $\theta=1$ (top right panel); (c) $\sigma=1,1.2$ (bottom left panel); and effect on stationary distribution of $\mu=0,0.25$ (bottom right panel). (Lines are increasingly dark as relevant parameter value increases.
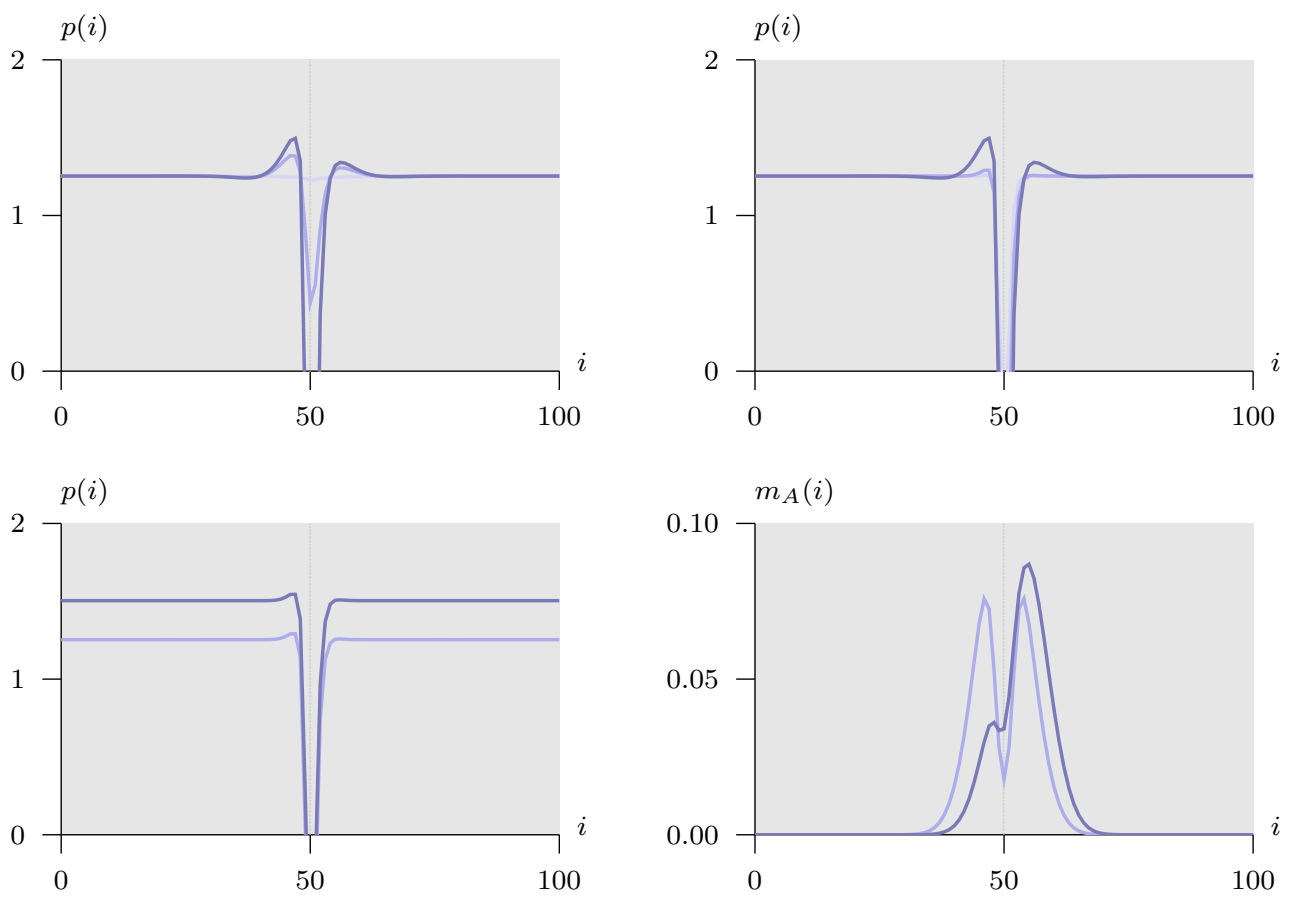

feature. To confirm this, I also tried a manager benefit function given by

$$
\Theta(i)=\theta\left(\frac{1-\exp \left(i^{*}-i\right)}{1+\exp \left(i^{*}-i\right)}\right)
$$

which basically corresponds to an S shaped curve that effectively smooths out the kinks in (15). The results for the equilibrium pricing function are very similar.

- Comparative dynamics. The two crucial parameters in my model are $\theta$, the intensity of the \#1 effect, and $\delta$, the discount factor. How do my results depend on the precise value of these parameters? From the analysis in the previous section, one is led to suspect that the qualitative nature of the results is fairly robust. Figure 8 shows the equilibrium pricing function for different values of $\theta$ (top left panel) and $\delta$ (top right panel). I tried other values for these parameters and the general conclusion is that the shape of $p(i)$ varies "smoothly" with the $\theta$ and $\delta$.

In my numerical simulations I assume that $\xi$ is normally distributed with $\mu=0$ and $\sigma=1$. The bottom left panel in Figure 8 shows the effect of increasing $\sigma$. As expected, prices are uniformly higher as a result of an increase in $\sigma$, which effectively corresponds to an increase in product differentiation. In fact, in the limit as $\delta \rightarrow 0$, the equilibrium value of price in a "peace" state is given by $1 /(2 \phi(0))$, which in the normal $\xi$ case is equal to $\sigma \sqrt{2 \pi} / 2$ (assuming that $\mu=0$ ). 
I also consider the case when $\mu \neq 0$. This implies that the model is not symmetric even if both firms have the same value of $\theta$. The bottom right panel of Figure 8 shows the effect of making $\mu>0$, where I assume that a positive value of $\mu$ favors firm $a$. The stationary distribution of market shares is still bimodal. However, the mode corresponding to firm $a$ being the large firm has greater density than the mode corresponding to firm $b$ being the market leader.

To conclude this section, I show different simulations of price and market share dynamics for different model parameterizations. Figure 9 considers two alternative cases with respect to the case considered in Figure $4 .{ }^{20}$ Specifically, the left panel considers the case when the \#1 effect ramps up as market shares increase from 45 to $55 \%$ (as opposed to the base case, where a firm with $51 \%$ market share reaps the total market leadership benefit). The left panel in Figure 7 shows that the more gradual the \#1 effect is, the wider the price war region - but also the shallower it is. The left panel in Figure 9 confirms this prediction in terms of actual price dynamics: longer price wars take place in equilibrium. This particular panel also shows a very high correlation between firm $a$ and firm $b$ prices.

The right panel in Figure 9 depicts the case when there are no firm level \#1 effects $(\theta=0)$, but instead there are consumer level $\# 1$ effects $(\lambda>0)$. One first important difference is that firm prices are quite different, with the leading firm charging a higher price and the laggard firm charging a lower price. A second important difference is that a price war consists of a convergence of the two firms' prices (with the high-price firm leading the price shift). The particular simulation shown in the right panel in Figure 9 suggests that these price wars are significantly less frequent and less pronounced than in the "supply side" \#1 effects case.

One feature shared by both panels in Figure 9 which is different from Figure 4 is the fact that there is tipping, that is, during the 500 periods simulation under consideration, the initial leader becomes a laggard. Given my assumptions regarding the distribution of $\xi$ (in particular, part (ii) of Assumption 1), the stochastic process of market shares is ergodic, and so with probability 1 the leader becomes a laggard in finite time. Whether "finite time" means a short period or a long period depends on parameter values. I should note that I used the same sequence of values of $\xi$ to generate the paths in Figures 4 and 9. The fact that the latter features a leadership switch whereas the former does not is primarily due to the higher value of $\delta$ used in Figure 4.

- The $N$ firm case. So far, all of my analysis has centered on the duopoly case. Some of the examples I motivated the paper with are indeed duopolies (e.g., Boeing and Airbus); but many feature more than two firms (e.g., IBM, HP and others). Suppose that there are $N>2$ firms. Let the state space now be described by $\mathbf{x}=\left(x_{i}\right)$, where $x_{i}$ is firm $i$ 's installed base, $i=1, \ldots, N$.

An active consumer chooses firm $i$ if and only if $\zeta_{i}-p_{i}(\mathbf{x})>\zeta_{j}-p_{j}(\mathbf{x})$ for all $j \neq i:^{21}$

$$
q_{i}(\mathbf{x})=\mathcal{P}\left(\zeta_{i}-p_{i}(\mathbf{x})>\zeta_{j}-p_{j}(\mathbf{x})\right) \quad \forall j \neq i
$$

Define

$$
\hat{\mathbf{x}}_{k}^{j} \equiv \mathbf{x}-\mathbb{1}_{k}+\mathbb{1}_{j}
$$

20. In addition to the parameter values consider in the figure's caption, I maintain $\eta=100, \mu=0, \sigma=1$

21. I assume the distribution of taste shocks is continuous, so that inequalities are strict almost surely. 


\section{Figure 9}

Price and market share dynamics for different model parameter values.

Left panel: $\theta=1, \lambda=0, \delta=0.7, \kappa=10$. Right panel: $\theta=0, \lambda=.1, \delta=0.7$
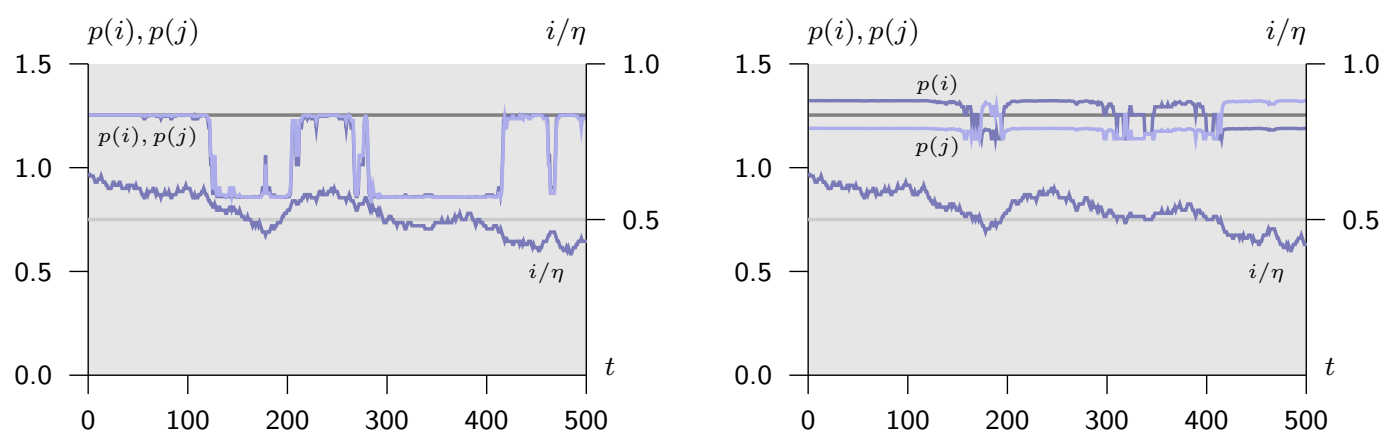

where $\mathbb{1}_{i}$ is an $N$ dimensional vector with 1 in the $i$ th component, zeros elsewhere; and $\Delta_{i}(\mathbf{x})$ is the generalized sign function: $\Delta_{i}(\mathbf{x})=+1$ if $x_{i}>x_{j}$, for all $j \neq i ; \Delta_{i}(\mathbf{x})=-1$ if $x_{i}<x_{j}$, for all $j \neq i$; and $\Delta_{i}(\mathbf{x})=0$ otherwise. Firm's value can then be written as

$$
v_{i}(\mathbf{x})=q_{i}(\mathbf{x}) p_{i}(\mathbf{x})+\sum_{k=1}^{N} \frac{x_{k}}{\eta} \sum_{j=1}^{N} q_{j}(\mathbf{x})\left(\theta \Delta_{i}\left(\hat{\mathbf{x}}_{k}^{j}\right)+\delta v_{i}\left(\hat{\mathbf{x}}_{k}^{j}\right)\right)
$$

Unlike the $N=2$ case, I now restrict the distribution of consumer preferences by assuming that $\zeta_{i}$ follows an extreme value distribution. This implies that

$$
q_{i}(\mathbf{x})=\frac{\exp \left(-p_{i}(\mathbf{x})\right)}{\sum_{k=1}^{N} \exp \left(-p_{k}(\mathbf{x})\right)}
$$

It follows that

$$
\begin{aligned}
\frac{d q_{i}(\mathbf{x})}{d p_{i}(\mathbf{x})} & =\frac{-\exp \left(-p_{i}(\mathbf{x})\right) \sum_{k=1}^{N} \exp \left(-p_{k}(\mathbf{x})\right)+\exp \left(-p_{i}(\mathbf{x})\right)^{2}}{\left(\sum_{k=1}^{N} \exp \left(-p_{k}(\mathbf{x})\right)\right)^{2}} \\
& =-\frac{\exp \left(-p_{i}(\mathbf{x})\right) \sum_{k \neq i} \exp \left(-p_{k}(\mathbf{x})\right)}{\left(\sum_{k=1}^{N} \exp \left(-p_{k}(\mathbf{x})\right)\right)^{2}}
\end{aligned}
$$

and

$$
\frac{d q_{i}(\mathbf{x})}{d p_{j}(\mathbf{x})}=\frac{\exp \left(-p_{j}(\mathbf{x})\right) \exp \left(-p_{i}(\mathbf{x})\right)}{\left(\sum_{k=1}^{N} \exp \left(-p_{k}(\mathbf{x})\right)\right)^{2}}
$$

and so

$$
\frac{d q_{j}(\mathbf{x})}{d p_{i}(\mathbf{x})} / \frac{d q_{i}(\mathbf{x})}{d p_{i}(\mathbf{x})}=\frac{\exp \left(-p_{j}(\mathbf{x})\right)}{\sum_{k \neq i} \exp \left(-p_{k}(\mathbf{x})\right)}
$$

The first order condition for firm $i$ 's value maximization is given by

$$
\begin{aligned}
& \frac{d q_{i}(\mathbf{x})}{d p_{i}(\mathbf{x})} p_{i}(\mathbf{x})+q_{i}(\mathbf{x}) \\
& \quad+\sum_{k=1}^{N} \frac{x_{k}}{\eta}\left(\frac{d q_{i}(\mathbf{x})}{d p_{i}(\mathbf{x})}\left(\theta \Delta_{i}\left(\hat{\mathbf{x}}_{k}^{i}\right)+\delta v_{i}\left(\hat{\mathbf{x}}_{k}^{i}\right)\right)-\sum_{j \neq i} \frac{d q_{j}(\mathbf{x})}{d p_{i}(\mathbf{x})}\left(\theta \Delta_{i}\left(\hat{\mathbf{x}}_{k}^{j}\right)+\delta v_{i}\left(\hat{\mathbf{x}}_{k}^{j}\right)\right)\right)=0
\end{aligned}
$$


In a symmetric equilibrium where $\zeta_{i}$ follows an extreme value distribution,

$$
\frac{q_{i}(\mathbf{x})}{d q_{i}(\mathbf{x}) / d p_{j}(\mathbf{x})}=\exp \left(-p_{i}(\mathbf{x})\right)
$$

The first-order condition can then be written as

$$
\begin{aligned}
p_{i}(\mathbf{x})= & \exp \left(-p_{i}(\mathbf{x})\right) \\
& -\sum_{k=1}^{N} \frac{x_{k}}{\eta}\left(\left(\theta \Delta_{i}\left(\hat{\mathbf{x}}_{k}^{i}\right)+\delta v_{i}\left(\hat{\mathbf{x}}_{k}^{i}\right)\right)-\sum_{j \neq i} \frac{\exp \left(-p_{j}(\mathbf{x})\right)}{\sum_{\ell \neq i} \exp \left(-p_{\ell}(\mathbf{x})\right)}\left(\theta \Delta_{i}\left(\hat{\mathbf{x}}_{k}^{j}\right)+\delta v_{i}\left(\hat{\mathbf{x}}_{k}^{j}\right)\right)\right)
\end{aligned}
$$

Compared to the $N=2$ case, this creates an extra layer of computational burden: even for given value functions, I need to solve the first-order conditions numerically. Moreover, the stochastic process is no longer a birth-and-death process, so the stationary distribution of market shares cannot be computed analytically. Other than that, the model is similar to what I developed in Section 2, although some new wrinkles are created by the presence of more than two firms.

Suppose for example that $N=3$ and consider the limit as $\delta \rightarrow 0$. Suppose moreover that $i=j$, whereas $k<i-1$. Then firm $i$ 's first-order condition implies that, in the limit as $\delta \rightarrow 0$

$$
p_{i}(\mathbf{x})=\exp \left(-p_{i}(\mathbf{x})\right)-\theta \frac{x_{j}}{\eta}\left(1-\frac{\exp \left(-p_{k}(\mathbf{x})\right)}{\sum_{\ell \neq i} \exp \left(-p_{\ell}(\mathbf{x})\right)}\right)-\theta \frac{x_{k}}{\eta}
$$

How does this compare to the expression in Proposition 1? In the latter case, the "subsidy" term is simply equal to $\theta$ : when $i=j$, either the "active" consumer is a firm $i$ consumer or the active consumer is a firm $j$ consumer. In the former case, the difference between winning and losing the next sale is the difference between the status quo and becoming the laggard. In the latter case, the difference between winning and losing the next sale is the difference between becoming the leader and remaining in the current state. Either way, the difference between winning and losing the next sale corresponds to a payoff of $\theta$ (in addition to the revenue from sales).

With three firms things are a little different. Suppose that the active consumer is a firm $i$ consumer. Then, no matter what choice this consumer makes, firm $i$ 's leadership status does not change: if firm $i$ makes the sale, all it achieves is to remain in the current state. If either firm $j$ or firm $k$ make the sale, then firm $i$ does not become the leader - and neither does it become the laggard. Consider now the case when the active consumer is firm $j$ 's. Then firm $i$ becomes the leader if either firm $i$ makes the sale or firm $k$ makes the sale. In terms of the first order condition this implies that we multiply the derivative $\partial q_{i} / \partial p_{i}$ by the term $1-\exp \left(-p_{k}(\mathbf{x})\right) / \sum \exp \left(-p_{\ell}(\mathbf{x})\right)$. In words: when firm $i$ lowers its price it increases the probability of making a sale, which in turn increases the probability that it becomes a market leader. However, to the extent that this sale is won over firm $k$, it has no marginal effect in terms of market leadership. Finally, if the active consumer is a firm $k$ consumer, then firm $i$ needs to make a sale in order to become a market leader, so we get the full $\theta$ marginal effect. 


\section{Conclusion}

Many firms seem to place a disproportionate weight on the goal of being market share leaders. In this paper, I develop a positive analysis of market competition when firms have such preferences. Whereas the standard explanation for price wars is associated to the idea of collusive equilibria, I present a theory of price wars that is entirely based on battles for market share.

I believe that various real-world examples seem to fit my theory of price wars better than the collusion theory. Consider for example the events following Rupert Murdoch's acquisition of the London Times. The Times, which started from a low $i$ state (daily circulation of $360 \mathrm{k}$ ), initially slashed its prices (from $48 \mathrm{p}$ to $30 \mathrm{p}$, then to $20 \mathrm{p}$ ). These low prices were followed by some competitors (Independent, Daily Telegraph) but not by all (e.g., not by the Guardian). Even the newspapers that cut prices did so to a less extent than the Times did. As a result, the Times' market share gradually increased, reaching a daily circulation of $860 \mathrm{k}$ after 3 years of price war. Eventually, prices were brought back to the initial levels. These events are roughly consistent with my model and a shock to $\theta_{a}$ corresponding to the Times acquisition by Murdoch.

A related question suggested by my model is whether it makes business sense for firms to aim for market leadership. Consider for example the case of General Motors, who, in 2012, recovered the position of global market share leader. According to CNN,

GM had held onto market share and its No. 1 rank by cutting prices on cars to the point where they were unprofitable. Bob Lutz, former vice chairman of GM, said worrying about its market share rank did the company more harm than good. "There is absolutely nothing to be gained by being the world's biggest," he said. "I tried to tell them to say, no, it's not our objective to be No. 1. But they just couldn't do it."

In other words, Lutz suggested that rank is irrelevant as far as firm value goes. By contrast, my analysis shows that, even if rank is not directly relevant in terms of shareholder value, it may be so by the behavior that it induces; and it may in fact increase shareholder value.

I am by no means the first to suggest that committing to a course of action that departs from profit maximization may increase a firm's payoff. In these situations, a crucial issue is whether players have the power to commit to an ex-post sub-optimal course of action. For example, complex contracts may be difficult to observe or verify - and are subject to renegotiation. In this sense, the goal of being \#1 seems compelling because it is simple and simplicity is an important condition for credibility. 


\section{Appendix}

Proof of Lemma 1: As mentioned in the text, equilibrium is (essentially) defined by the sets of equations (9) and (12), which determine the values of $v(i)$ and $x(i)$, respectively. Given $x(i)$ and $v(i)$, the values of $p(i)$ and $q(i)$ are determined uniquely. Let

$$
\mathbf{z} \equiv(x(0), \ldots, x(\eta), v(0), \ldots, v(\eta))
$$

We thus have a system of $2(\eta+1)$ equations and $2(\eta+1)$ unknowns. Represent this system as $f_{i}(\mathbf{z} ; \delta)=0$, where $i=0, \ldots, 2 \eta$.

Setting $\delta=0,(12)$ may be re-written as

$$
x(i)+\frac{2 \Phi(x(i))-1}{\phi(x(i))}=\Gamma(i)
$$

where $\Gamma(i)$ is bounded and exogenously given. Part (iv) of Assumption 1 implies that the left-hand side is strictly increasing in $x(i)$, ranging continuously from $-\infty$ to $+\infty$ as $x(i)$ varies from $-\infty$ to $+\infty$. It follows that there exists a unique value $x(i)$. Uniqueness of $x(i)$ in turn implies uniqueness of $v(i), p(i)$ and $q(i)$.

Continuity implies that, for each $\delta$ in the neighborhood of $\delta=0$, I can find an $\epsilon \in(0, \infty)$ such that equilibrium $x(i)$ and $v(i)$ must be in $[-\epsilon, \epsilon]$. I thus henceforth restrict to this compact set of $x(i)$ and $v(i)$ values.

Setting $\delta=0,(8)$ implies

$$
v(i)-\frac{(1-\Phi(x(i)))^{2}}{\phi(x(i))}=\Omega(i)
$$

Taking into account that $\delta=0$ implies $x(i)=\frac{1}{2},(16)$ and (17) imply the matrix of partial derivatives of $f_{i}(\mathbf{z} ; \delta)$ at $\delta=0, \nabla f$, is a block matrix:

$$
\nabla f=\left[\begin{array}{cc}
3 I & 0 \\
I & I
\end{array}\right]
$$

which has full rank. By part (i) of Assumption 1, all $f_{i}$ are continuously differentiable. Therefore, the Implicit Function Theorem implies that there exists a unique equilibrium in the neighborhood of $\mathbf{z}^{*}$ and $\delta=0$, where $\mathbf{z}^{*}$ is the (unique) equilibrium at $\delta=0$. By continuity and the assumption that all elements of $\mathbf{z}$ belong to a compact set, there exists no other equilibrium in the neighborhood of $\mathbf{z}^{*}$, which finally implies there exists a unique equilibrium in the neighborhood of $\delta=0$.

Proof of Lemma 2: The game I consider has the structure of a "birth and death" Markov process (Kelly, 1979, Section 1.3); that is, from any given state $i$ the only transitions to consider are to the neighboring states: $M(i, k)=0$ if $|i-k|>1$. These processes are recursive (Kelly, 1979, Lemma 1.5). It follows that they are also stationary. Recursiveness also implies that detailed balance holds (Kelly, 1979, Theorem 1.3), namely

$$
M(i-1, i) m(i-1)=M(i, i-1) m(i)
$$


The value of $M(i-1, i)$ corresponds to Nature selecting as an active consumer one of the consumers with the firm that currently has $\eta-i+1$ consumers; and that agent switching to the other firm (that is, the firm currently having $i-1$ consumers). This happens with probability

$$
M(i-1, i)=\frac{\eta-i+1}{\eta} q(i-1)
$$

Similarly,

$$
M(i, i-1)=\frac{i}{\eta}(1-q(i))
$$

Equation (18) allows me to compute the stationary distribution recursively. Given $m(0)$, we have

$$
m(i)=m(0) \prod_{k=1}^{i} \frac{M(i-1, i)}{M(i, i-1)}=m(0) \prod_{k=1}^{i} \frac{q(i-1)}{1-q(i)} \cdot \frac{\eta-i+1}{i}
$$

Since $\sum_{k=0}^{\eta} m(k)=1$,

$$
m(0)=\left(1+\sum_{i=1}^{\eta} \prod_{k=1}^{i} \frac{q(i-1)}{1-q(i)} \cdot \frac{\eta-i+1}{i}\right)^{-1}
$$

Equation (18) also implies that $m(i)>m(i-1)$ if and only if

$$
\frac{\eta-i+1}{\eta} q(i-1)>\frac{i}{\eta}(1-q(i))
$$

By a similar argument, $m(i)>m(i+1)$ if and only if

$$
\frac{\eta-i}{\eta} q(i)<\frac{i+1}{\eta}(1-q(i+1))
$$

which concludes the proof.

Proof of Proposition 1: Suppose that $\delta=0$. Then (6) becomes

$$
w(i)=\theta(\Delta(i+1)-\Delta(i))=\theta \mathbb{1}_{i \in\left\{i^{*}-1, i^{*}\right\}}
$$

where $\mathbb{1}_{x}$ is an indicator variable which equals 1 if $x$ is true, zero otherwise.

$$
w(j-1)=\theta \mathbb{1}_{j-1 \in\left\{i^{*}-1, i^{*}\right\}}=\theta \mathbb{1}_{j \in\left\{i^{*}, i^{*}+1\right\}}=\theta \mathbb{1}_{i \in\left\{i^{*}, i^{*}-1\right\}}=w(i)
$$

Substituting in (12), this implies $x(i)=0$ (see the proof of Lemma 1). From (7), we get

$$
p(i)=\frac{1}{2 \phi(0)}-\frac{i}{\eta} \theta \mathbb{1}_{i \in\left\{i^{*}, i^{*}+1\right\}}-\frac{j}{\eta} \theta \mathbb{1}_{i \in\left\{i^{*}-1, i^{*}\right\}}
$$

which implies the first expression in the result.

Substituting $\delta=0$ in (9) I get

$$
\stackrel{\circ}{v}(i)=\frac{1}{4 \phi(0)}+\frac{i}{\eta} \theta \Delta(i-1)+\frac{j}{\eta} \theta \Delta(i)
$$


which in turn implies the expression in the result.

I next turn to the stationary distribution of market shares. Since $\lim _{\delta \rightarrow 0} \quad q(i)=\frac{1}{2}$, Lemma 2 implies that, in the limit as $\delta \rightarrow 0$,

$$
m(i)=m(0) \prod_{k=0}^{i} \frac{\eta-i+1}{i}=\frac{\eta !}{i !(\eta-i) !}
$$

where

$$
m(0)=\left(1+\sum_{i=1}^{\eta} \frac{\eta !}{i !(\eta-i) !}\right)^{-1}=\left(\sum_{i=0}^{\eta} \frac{\eta !}{i !(\eta-i) !}\right)^{-1}=2^{-\eta}
$$

which leads to the expression for $m(i)$ in the result. Finally, setting $q(i-1)=q(i)=$ $q(i+1)=\frac{1}{2}$, the Lemma 2 conditions for $m(\eta / 2)$ to be greater than its neighbors become

$$
\left(\eta-\frac{\eta}{2}+1\right) \frac{1}{2}>\frac{\eta}{2}\left(1-\frac{1}{2}\right) \quad \text { and } \quad\left(\eta-\frac{\eta}{2}\right) \frac{1}{2}<\left(\frac{\eta}{2}+1\right)\left(1-\frac{1}{2}\right)
$$

both of which are equivalent to $\eta+2>\eta$.

Proof of Corollary 1: From the expression for $v(i)$ in Proposition 1, we get

$$
\lim _{\delta \rightarrow 0} v(i)+v(j)= \begin{cases}\frac{1}{2 \phi(0)}-2 \frac{i^{*}-1}{\eta} \theta & \text { if } i=i^{*} \\ \frac{1}{2 \phi(0)}-\frac{\eta-i^{*}-1}{\eta} \theta & \text { if } i=i^{*} \pm 1 \\ \frac{1}{2 \phi(0)} & \text { otherwise }\end{cases}
$$

which is decreasing in $\theta$, strictly if $i \in\left\{i^{*}-1, i^{*}, i^{*}+1\right\}$.

Proof of Proposition 2: Define, for a generic variable $x$,

$$
\left.\left.\stackrel{\circ}{x} \equiv x\right|_{\delta=0} \quad \dot{x} \equiv \frac{\partial x}{\partial \delta}\right|_{\delta=0}
$$

Differentiating (6), I get

$$
\dot{w}(i)=\stackrel{\circ}{v}(i+1)-\stackrel{\circ}{v}(i)
$$

Differentiating (12), I get

$$
\begin{aligned}
& -3 \dot{x}(i)=\frac{i}{\eta}(\dot{w}(i-1)-\dot{w}(j))+\frac{j}{\eta}(\dot{w}(i)-\dot{w}(j-1)) \\
& =\frac{i}{\eta}(\stackrel{v}{ }(i)-\stackrel{\circ}{v}(i-1)-\stackrel{\circ}{v}(j+1)+\stackrel{\circ}{v}(j)) \\
& +\frac{j}{\eta}(\stackrel{\circ}{v}(i+1)-\stackrel{\circ}{v}(i)-\stackrel{\circ}{v}(j)+\stackrel{\circ}{v}(j-1))
\end{aligned}
$$

where the second equality follows from (19). Considering that $\delta=0$ implies $x(i)=0$ for all $i$ (cf Proposition 1), by substituting $i^{*}+1$ for $i$ in (20) we can state that $x\left(i^{*}+1\right)<0$ if and only if

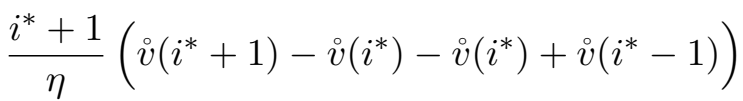

$$
\begin{aligned}
& +\frac{i^{*}-1}{\eta}\left(\grave{v}\left(i^{*}+2\right)-\grave{v}\left(i^{*}+1\right)-\grave{v}\left(i^{*}-1\right)+\stackrel{\circ}{ }\left(i^{*}-2\right)\right)>0
\end{aligned}
$$


(Recall that, if $i=i^{*}+1$, then $j=\eta-i=i^{*}-1$.) Dividing throughout by $\theta / \eta$ (a positive constant), and substituting the equilibrium values of $v(i)$ in Proposition 1 for the various $\stackrel{\circ}{v}$, I get

$$
\left(i^{*}+1\right)\left(3 \frac{i^{*}-1}{\eta}-1\right)+\left(i^{*}-1\right)\left(-\frac{i^{*}-1}{\eta}+1\right)>0
$$

which, recalling that $\eta=2 i^{*}$, is equivalent to $i>2$. This proves the first two inequalities.

Differentiating (8) with respect to $\delta$ at $\delta=0$, I get

$$
\dot{v}(i)=-\dot{x}(i)+\frac{i}{\eta} \stackrel{v}{v}(i-1)+\frac{j}{\eta} \stackrel{\circ}{v}(i)
$$

From Proposition 1, $\stackrel{v}{v}(i)$ is constant for $i<i^{*}$, that is, $i<i^{*}$ implies $\dot{v}(i)=\stackrel{v}{v}\left(i^{*}-1\right)$. Substituting into (21), we get that $i<i^{*}$ implies

$$
\dot{v}(i)=-\dot{x}(i)+\stackrel{\circ}{v}\left(i^{*}-1\right)
$$

Also substituting $\stackrel{v}{v}\left(i^{*}-1\right)$ for $\stackrel{v}{v}(i)$ in (20), I get $\dot{x}\left(i^{*}-2\right)=0$. Finally (22) implies

$$
\dot{v}\left(i^{*}-1\right)-\dot{v}\left(i^{*}-2\right)=-\dot{x}\left(i^{*}-1\right)+\stackrel{\circ}{v}\left(i^{*}-1\right)+\dot{x}\left(i^{*}-2\right)-\stackrel{\circ}{ }\left(i^{*}-1\right)=-\dot{x}\left(i^{*}-1\right)
$$

which, as shown above, is negative.

Proof of Proposition 3: (a) Suppose that $\delta=0$. By an argument similar to that of Proposition 1 , a positive $\theta_{a}$ implies strictly lower prices at states $i \in\left\{i^{*}-1, i^{*}, i^{*}+1\right\}$ and no change in prices at other states. Since equilibrium prices when $\theta_{a}=0$ maximize firm profits, we conclude that shareholder value is strictly lower. Since the inequality is strict, by Lemma 1 it also holds for sufficiently small $\delta$.

(b) Suppose that $\delta=0$ and consider an infinitesimal increase in $\theta_{a}$. By the same argument as in part (a), this leads to lower prices in states $i \in\left\{i^{*}-1, i^{*}, i^{*}+1\right\}$. By the envelope theorem, given the change in $\theta_{a}$ is infinitesimal, the change in per period profit is of second order. However, the increase in $q(i)$ is a first-order effect. Since per period payoff is strictly increasing in $i$, it follows that average payoff in the stationary state is strictly increasing. Finally, the shareholder's value (in any given state) converges to the average stationary value as the discount factor tends to infinity.

Proof of Proposition 4: Suppose that $\delta=0$. Since $\theta=0$, (6) becomes

$$
w(i)=0
$$

Noting that $\lambda \Delta(i)-\lambda \Delta(j)=2 \lambda \Delta(i)$, (12) may be re-written as

$$
x(i)+\frac{2 \Phi(x(i))-1}{\phi(x(i))}=-2 \lambda \Delta(i)
$$

where the left-hand side is increasing in $x(i)$ and equal to zero if $x(i)=0$ (see the proof of Lemma 1. Let $x^{\prime}$ be the solution of the above equation when $i>i^{*}$, so that the right hand side equals $-2 \lambda$; and and let $q^{\prime} \equiv 1-\Phi\left(x^{\prime}\right)$. The results for $q(i)$ and $p(i)$ then follow.

Finally, from Lemma 2, we know that

$$
M(i-1, i) m(i-1)=M(i, i-1) m(i)
$$


As $\lambda \rightarrow \infty, q\left(i^{*}-1\right) \rightarrow 0$ and $q\left(i^{*}+1\right) \rightarrow 1$. This implies that $M\left(i^{*}-1, i^{*}\right) \rightarrow 0$, whereas $M\left(i^{*}, i^{*}-1\right)=\frac{1}{4}$ for all values of $\lambda$. This in turn implies that $m\left(i^{*}\right)<m\left(i^{*} \pm 1\right)$ for $\lambda$ large enough. 


\section{References}

Al-Najuar, Nabil, Sandeep Baliga, and David Besanko (2008), "Market Forces Meet Behavioral Biases: Cost Misallocation and Irrational Pricing," Rand Journal of Economics 39 (1), 214-317.

Armstrong, Mark, and Steffen Huck (2010), "Behavioral Economics Applied to Firms: A Primer," Competition Policy International 6 (1), 1-45.

Baumol, William J. (1962), "On the Theory of Expansion of the Firm," American Economic Review 52 (5), 1078-1087.

Besanko, David, and Ulrich Doraszelski (2004), "Capacity Dynamics and Endogenous Asymmetries in Firm Size," Rand Journal of Economics 35 (1), 23-49.

Besanko, David, Ulrich Doraszelski, Yaroslav Kryukov, Mark Satterthwaite (2010), "Learning-by-Doing, Organizational Forgetting, and Industry Dynamics," Econometrica 78 (2), 453-508.

Cabral, Luís (2011), "Dynamic Price Competition with Network Effects," Review of Economic Studies 78, 83-111.

Cabral, Luís, and Michael H Riordan (1994), "The Learning Curve, Market Dominance and Predatory Pricing," Econometrica 62, 1115-1140.

Cabral, Luís, and J Miguel Villas-Boas (2005), "Bertrand Supertraps," Management Science 51, 599-613.

Cabral, Luís, and Gabriel Natividad (2013), "Box-Office Demand: The Importance of Being \#1," New York University.

Caminal, Ramon, and Xavier Vives (1996), "Why Market Shares Matter: An InformationBased Theory," Rand Journal of Economics 27, 2. 221-239

Carare, Octavian (2012), "The Impact of Bestseller Rank on Demand: Evidence from the App Market," International Economic Review 53, 717-742.

Caves, Richard E, and Michael E Porter (1977), "From Entry Barriers to Mobility Barriers: Conjectural Decisions and Contrived Deterrence to New Competition," Quarterly Journal of Economics 91 (2), 241-262.

Ellison, Glenn (2006), "Bounded Rationality in Industrial Organization," in Blundell, Newey and Persson (Eds), Advances in Economics and Econometrics: Theory and Applications, Ninth World Congress, Cambridge University Press.

Ferrier, Walter J, Ken G Smith and Curtis M Grimm (1999), "The Role of Competitive Action in Market Share Erosion and Industry Dethronement: A Study of Industry Leaders and Challengers," The Academy of Management Journal 42 (4), 372-388.

Fershtman, Chaim, and Kenneth Judd (1987), "Equilibrium Incentives in Oligopoly," American Economic Review 77, 927-940. 
Fershtman, Chaim, and Ariel Pakes (2000), "A Dynamic Oligopoly with Collusion and Price Wars," Rand Journal of Economics 31 (2), 207-236.

Gort, M (1963), "Analysis of Stability and Changes in Market Shares," Journal of Political Economy 71, 51-63.

Kelly, Frank P (1979), Reversibility and Stochastic Networks, Chichester: Wiley.

Klemperer, Paul (1989), "Price Wars Caused by Switching Costs," Review of Economic Studies 56 (3), 405-420.

Gilbert, Richard J, and David M G Newbery (1982), "Preemptive Patenting and the Persistence of Monopoly Power," American Economic Review 72, 514-526.

Green, Ed And Robert Porter (1984), "Noncooperative Collusion Under Imperfect Price Information," Econometrica 52, 87-100.

Harrington, Joseph (2008), "Detecting Cartels," in P Buccirossi (Ed), Handbook of Antitrust Economics,Cambridge, MA: MIT Press, 213-258.

Harrington, Joseph (2012), "Exploring the Boundaries of Unlawful Collusion: Price Coordination when Firms Lack Full Mutual Understanding," Wharton.

Hörner, Johannes (2004), "A Perpetual Race to Stay Ahead," Review of Economic Studies 71 (4), 1065-1088.

Kaplow, Louis (2013), Competition Policy and Price Fixing, Princeton: Princeton University Press.

Lazear, Edward, and Sherwin Rosen (1981), "Rank-Order Tournaments as Optimum Labor Contracts," Journal of Political Economy 89, 841-864.

Macleod, W Bentley (1985), "A Theory of Conscious Parallelism," European Economic Review 27 (1), 25-44.

Podolny, Joel M (1993), "A Status-Based Model of Market Competition," American Journal of Sociology 98 (4), 829-872.

Rotemberg, Julio, and Garth Saloner (1986), "A Supergame-Theoretic Model of Price Wars During Booms," American Economic Review 76, 390-407.

Schelling, Thomas C (1960), The Strategy of Conflict, Harvard University Press.

Shapiro, Carl (1989), "Theories of Oligopoly Behavior," in Schmalensee andWillig (Eds), Handbook of Industrial Organization, Volume 1. Amsterdam: North Holland.

Simon, Hermann (2009), Hidden Champions of the Twenty-first Century: Success Strategies of Unknown World Market Leaders, Bonn: Springer.

Sklivas, Steven D. (1987), "The Strategic Choice of Managerial Incentives," Rand Journal of Economics 18 (3), 452-458. 
Sorensen, Alan T. (2007), "Bestseller Lists and Product Variety," Journal of Industrial Economics 55, 715-738.

Vickers, John (1985), "Delegation and the Theory of the Firm," Economic Journal 95, $138-147$. 